Original Research Paper

\title{
Design of an Automatic Umbrella Actuated through Water and Temperature Sensors
}

\author{
${ }^{1}$ Meher Dev Gudela, ${ }^{2}$ Atharv Kulkarni, ${ }^{1}$ Abhishek Dhotre and ${ }^{2}$ Kshitiz Shrimali \\ ${ }^{l}$ Department of Mechanical Engineering, Dwarkadas J. Sanghvi College of Engineering, Mumbai, India \\ ${ }^{2}$ Department of Mechanical Engineering, Lokmanya Tilak College of Engineering, Mumbai, India
}

\author{
Article history \\ Received: $12-09-2020$ \\ Revised: 25-09-2020 \\ Accepted: 29-09-2020 \\ Corresponding Author: \\ Meher Dev Gudela \\ Department of Mechanical \\ Engineering, Dwarkadas J. \\ Sanghvi College of \\ Engineering, Mumbai, India \\ Email: meher.gudela96@gmail.com
}

\begin{abstract}
The aim of this thesis is to make a smart umbrella which can reduce human effort due to its functionality and can target the market due to its unique design, is really important in modern society at risk of rainfall and wind without coverage in place. The purpose of this project is to make such an umbrella that is really sensitive in the incidences of rain and sunlight at domestic and market level. Specifically, in summer season the floor of open areas gets so warm due to sun light that makes difficulty for working. This umbrella covers the entire hall during the rain and sunlight. This umbrella operates with the help of different sensors like temperature sensors, water sensors and wind sensors. The opening and closing of umbrella is being controlled through a motor. Motor can give a quick and instant response to the shaft so that shaft can play a major role of power transmission for opening and closing of umbrella. Motor provides required rpm to the shaft. Whenever temperature of the atmosphere goes above $35^{\circ}$, temperature sensor sends signal to Arduino which is control unit box. Then Arduino sends signal further to the motor so that motor may activate and deliver required rpm to the coupling shaft. This project is a cost-effective way of providing automated controlled shade from high intensity sunlight and rain. So, the problems of open and vast areas can be solved by using such types of automated umbrellas.
\end{abstract}

Keywords: Temperature Sensors, Water Sensors, Wind Sensors, Shaft, Arduino

\section{Introduction}

An umbrella is a folding canopy (overhead roof) supported by metal or wooden ribs that is usually mounted on a wooden, metal or plastic pole. It is designed to protect a person against sunlight and rain. Umbrellas and parasols are primarily hand-held portable devices sized for personal use. The largest hand-portable umbrellas are golf umbrellas. Umbrellas can be divided into two categories: Fully collapsible umbrellas, in which the metal pole supporting the canopy retracts, making the umbrella small enough to fit in a handbag and non-collapsible umbrellas, in which the support pole cannot retract and only the canopy can be collapsed. In summer season temperature of the atmosphere rises to high level and it's not bear able. People are looking out for shady places because sun's temperature is so high. Temperature in summer days is normally above $35^{\circ} \mathrm{C}$ so there is need of a system which provides shadow.
Generally, sun shading big umbrellas is used at beaches, swimming pools or in courtyards, a lot of coffee shops or restaurants also use sun-shading big umbrellas on tables and rain-shielding but also for providing a good mood of being in the surrounding. Therefore, the big umbrellas are quite practical. For such types of purposes, an automated umbrella is required which is equipped with modern technology.

The vision is to make a optimize structure which is of low cost that fulfills the need of the people working in open areas. The main function of an automated umbrella is protection from sunlight. This umbrella meets these needs by using multiple sensors and a set of DC motors to automatically track the sun to maximize shading where it is being used. DC motor is used for direct and Instant response of a current having single phase. The selection of DC motor depends upon torque. It operates whenever sun rises in morning, sensors detect light and activate the motors of umbrella 
which further drives the shaft to open and close the umbrella. Now a days these types of umbrellas are also be used for car parking.

The purpose of doing this is to feel comfortable while working in open areas and to make a design which is really reliable for domestic and industrial purposes.

\section{Literature Review}

An automated umbrella means that it works flawlessly. In 1928, Hans Haupt invented the pocket umbrella. In Vienna, Hans Haupt was a student studying sculpture when she developed a prototype for an improved compact foldable umbrella for which she received a patent in September 1929. The umbrella was made by an Austrian company. In Germany, the small foldable umbrellas were made by the company Knirps. At the US University of central Florida students worked on automated umbrella. They designed an automated umbrella that worked with the help of a control system. The umbrella canopies of the 1600's were woven out of silk, which provided limited water resistance when compared to today' $\mathrm{s}$ rain umbrellas, but the distinct canopy shape was unchanged from the earliest documented designs., even rain umbrellas were still considered a product only for distinguished women, while men facing ridicule if they were seen with one. Hanway came up and took the rain umbrella on the streets of London in 1750. Infect, in the late 1700's and early 1800's, a "Hanway" evolved to become another name for a rain umbrella (Vaghela et al., 2017). Through the 1800's until the present time, the materials used to make rain umbrellas have evolved, but the same basic canopy shape remains. One of the most important discoveries came in the early 1850s, when Samuel Fox took the idea of using "U" molded metal rods on the ribs and stretcher to make a simple, stronger frame. Previously, English umbrellas were made of cane or whalebones.

Modern umbrellas are made by a hand-assembled process that, with the exception of a few sensitive areas, can be made by skilled workers. First, a shaft - whether of wood, metal, or fiberglass - is made and the ribs and tails are attached. Next, the nylon canopy is handstitched in sections. They were large and unpopular. Ribs and stretchers are often seen only today on parasols and patio umbrellas. Advances in metal technology have made round metal ribs and holes easily accessible, but some manufacturers are producing umbrellas with these features. Current rain umbrellas are made of fabrics (nylon, most commonly) that are resistant to rain that draws, dries quickly, folds easily and is available in a variety of colors and designs. Whalebones have been replaced with wood, then steel, aluminum and now fiberglass to manufacture the shaft and ribs and now-adays nylon fabrics have replaced silks, leaves and feathers as a more weatherproof option (Martinec, 2011; Portis Jr. and Hampton, 2013).

Nylon fabric as shown in Fig. 1 and 2 is smooth, clean, soft, lightweight and quick drying properties. Nylon is a common family polymer that is made, based on aliphatic or semi-aromatic polyamides. Nylon is a thermoplastic silky material that can be melted processed into fibers, films or shapes. Nylon polymers can be combined with a variety of materials to achieve a wide variety of materials. Nylon polymers acquire important commercial applications in textiles and yarns (clothing, floor reinforcement and rubber reinforcement. Due to the weather-resistant properties of nylon and high density of taffeta nylon, taffeta is extremely durable and useful for outdoor applications. This material is usually used for tents, jackets, bags, storage covers and bags. A wide range of sheets for this content is available in the market. Temperature absorption is related to color. The darker the color the more the heat will absorb the umbrella so we will choose the right color depending on the intensity of the sun (Meng et al., 2017).

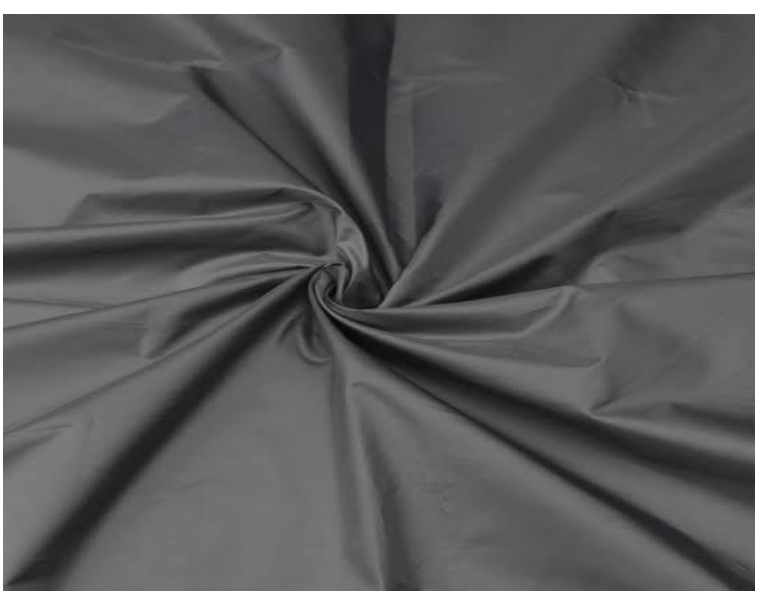

Fig. 1: Synthetic nylon fibers material sheet

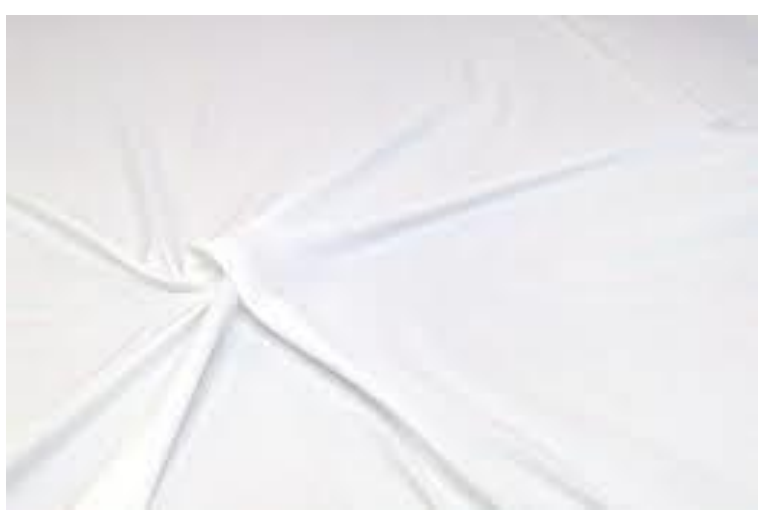

Fig. 2: Kind of fabric blended material or interwoven with cotton wheels and cotton stretched 
Pongee is a soft Chinese cloth that is made of silk and other threads. Pongee color is black and matte. Very high-quality fabric. Sounds like cotton touch. It is a medium-sized and balanced body because it is tightly woven. Pongee is more expensive than polyester and the quality is better. A medium and high-quality umbrella often uses a pongee cloth. Rain Slide is easy from Pongee's fabric and keeps the umbrella dry (Li, 2011).

PVC and PoE plastic materials allow manufacturers to create clear umbrellas. Similarly, the PVC cover will stick when overheated during travel or storage. When mass is produced, all PVC umbrellas need to put talcum powder inside to avoid this problem and currently umbrella manufacturers are using better PoE materials instead. EVA is an opaque plastic material; it is softer than PVC and does not stick when umbrella closes (Day, 1985).

Fabric made from dyed cloth is different in its style compared to printed fabric, physical characteristics are the dynamic physical parameters of fabric. Most of the strength and durability of the fabric are characteristics and not properties. There are four main categories of fabric characteristics that interest the manufacturer. They are:

- Style characteristics

- Utility characteristics

- Durability characteristics

- Product production characteristics

You can't go wrong with its brightly colored look and non-fade quality.it is often used in the look-up but it is expensive (Yassi et al., 2005).

\section{Rainfall Monitoring using Acoustic Sensors}

An acoustic sensor is used to measure the environment and converts this information into a digital signal. The sensor can transfer information records to a web server and can trigger a SMS caution when rainfall information surpasses security limits. Rainfall information from the sensors are diagramed, broke down. It reports, out of the blue, the execution of an acoustic rain sensor. Furthermore, a tipping pail in a similar gadget is coordinated with an Android telephone. This new arrangement demonstrates the distinction between an ongoing acoustic rain sensor and a tipping basin, which is an aggregation sensor. The investigation highlights and execution of the acoustic sensors coordinates the improvement of minimal effort gadgets for social occasion rain information, which can supplement standard rain estimation gadgets.

\section{An Intelligent Control System of Curtain Based on Arduino}

Design for an intelligent control system of curtain based on Arduino portrays an insightful control arrangement. Although distinguishing and examining the components that incorporate the daylight, time, temperature, stickiness and outside natural conditions, the microcontroller consequently decides the opening and shutting of window ornaments. By tests, it is demonstrated that the clever control arrangement of the shade has the high practicability and amazing manipulative (OHSAH, 2004).

\section{Environmental Change Sensing}

An environmental sensor device is electrically connected to a power source and installed in the shading system for detecting environmental changes of the shading system. The active controller is electrically connected. The device has a natural sensor and basically controls the awning frame, where the active controller receives the command signal from a natural sensing device, the awning frame is adjusted accordingly regulate the area of its shadow (Gingerich and Ondeck, 1998).

\section{Electric Servo and Detector Motion}

Figure 3 shows the electric servo. The functional controller comprises an electric servo which is electrically linked to the power source and is operatively controlled by the functional controller to automatically and selectively actuate the awning frame between an unfolded position that the sun shelter is expanded to maximize the shading area and a folded position that the sun shelter is folded up to minimize the shading area t. As a result, the electric servo is electrically connected to the wind detector and the motion detector so that the awning frame is capable of timely responding to the environmental change surrounding the intelligent outdoor Sun shading device.

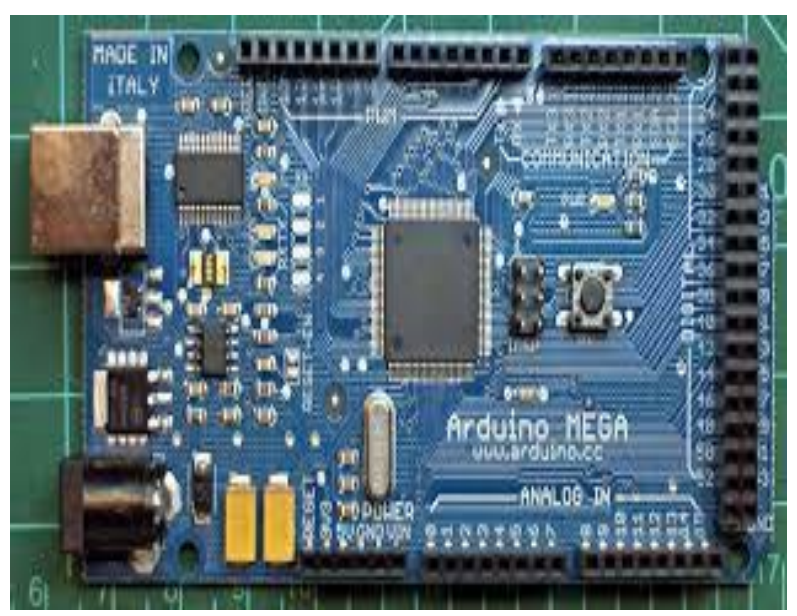

Fig. 3: The Arduino mega 1280 is a microcontroller board based on the ATmega1280 


\section{Automatic Umbrella Control Mechanism}

It is the main object of the present invention to provide an automatic umbrella control mechanism, which enables the user to open and close the umbrella automatically by switching on a button. A temperature sensor is installed to the circuit which senses the atmospheric temperature and sends signal in the form of waves to the control box. Control box is controlled by Arduino which further send signal to the motor coupled to the shaft of the umbrella. Motor transfers its motion to the coupled shaft so that shaft may rotate. Shaft rotates the drums. A nylon taffeta sheet is attached with guided lines with the help of Orings. One end of the umbrella sheet is attached with slider and slider moves with rope which is passing through the drum and pulley. As the drum rotates anticlockwise, rope moves in forward direction with slider and umbrella sheet opens. For closing of umbrella, drums rotate clockwise then rope starts to move backward direction and hence umbrella closes. The clockwise and anticlockwise directions of motor are controlled by Arduino.

\section{Chain and Sprocket Mechanism}

The output from power sources such as electric motors, car engines and wind generators are rotary motion of a drive shaft. Common ways to transfer movement and force from a removable drive shaft is as follows:

- Gears

- Belt and pulleys

- Chain and sprockets

- Crank

- Coupling

A sprocket is a toothed wheel that is used to transfer movement and torque from one shaft to another. Chains that are used to transfer movement and force from one sprocket to another are called energy chains. Unlike gears that have space to transfer movement and torque from one gear to another, blocks can be set apart. The sprockets are connected by a chain.

There were four sprockets and two shafts are requiring for mechanical transmission system. But this mechanism was not optimizing because it requires proper lubrications ones in a month. Moreover, it is applicable for only $1.5 \mathrm{~m}$ distance (Smith-Temple and Johnson, 2005).

\section{Pulley and Rope Mechanism}

Figures 4 and 5 showcase the pulley and rope. Second design was using pulleys and rope mechanism for transmission purpose which was light weighted and cost effective but eventually after some practical implementation that the prescribed system cannot bear the environmental conditions of the region at all. There were some serious issues regarding bending of umbrella sheet during transmission.

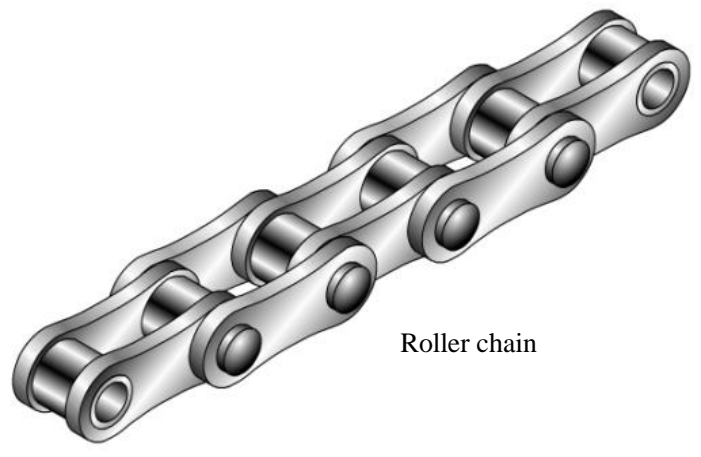

Fig. 4: Roller chain

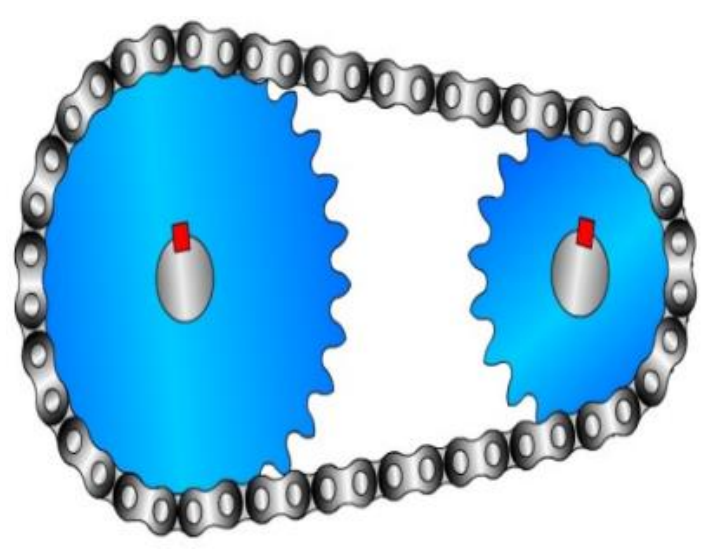

Fig. 5: Sprockets and chain system

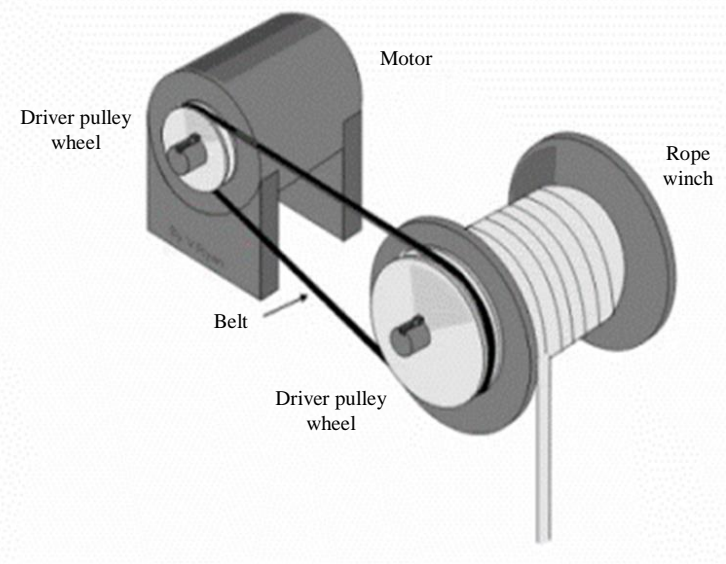

Fig. 6: Pulley and rope mechanism

Although using light weight sheet was an alternative solution but such type of sheet is costly and can be tear out when force will apply on it (Fig. 6).

Some advantages are:

- It is one of the simplest tools for heavy lifting

- It provides great support for the object 
- Moveable pulleys may also design so that it can move along the load

- Forces can be applied in any direction; it helps to change the direction force and movement

In order to control the above problems and to make optimize design the drum drive and clump system is used. These systems can bear high amount of load and provide smooth transmission (XRF, 2018).

\section{Methodology and Design}

Our methodology must be more convenient and simpler that a feasible and low-cost umbrella can be made. The plan is to design structure first and then a source of power to open and close it i.e., motors of suitable torque, rpm and other specifications.

Figure 7 shows the shaft structure. The structure will simply consist on columns (vertical supports) and beams (horizontal supports). An initial frame structure is already available due to ceiling fans in the yard of the Mosque. We have to rely on this structure instead of making a new due to following reasons:

- There will be an increase in width of umbrella because vertical supports will be placed outside the Mosque as there is no space inside the yard to do so

- High strength pipes would be bought which will increase the cost

- The horizontal pipes in the Mosque are exactly fitted on the beam (most strength full part of any civil structure) of roof. It is almost impossible to install new pipes at somewhere else in order to achieve high strength

- Extra fabrication cost

After visualization we came to know that there are 4 horizontal pipes in the yard. Each pipe (total 20 vertical pipes) is supporting $400 \mathrm{~N}$ of point load due to ceiling fans. The pipe at the last position is our desired horizontal support on which we will place some mechanical transmission mechanism for the movement of umbrella.

After this a simply supported beam (shaft) will place on the roof of the Mosque. This beam will like a circular rod (shaft) and ball bearings will use to support it from both ends so that it can easily rotate to roll and unroll the umbrella. Power will transmit from DC motor to beam through some suitable transmission mechanism i.e., (pulleys).

A uniform distributed load in form umbrella sheet will apply on the beam so all the design calculations will be made according to the nature of the beam and the applied load.

A suitable sheet will be selected according to the weather conditions of the region. Material of the sheet will be nylon taffeta because it is smooth, fine, soft, lightweight and have quick-drying properties.

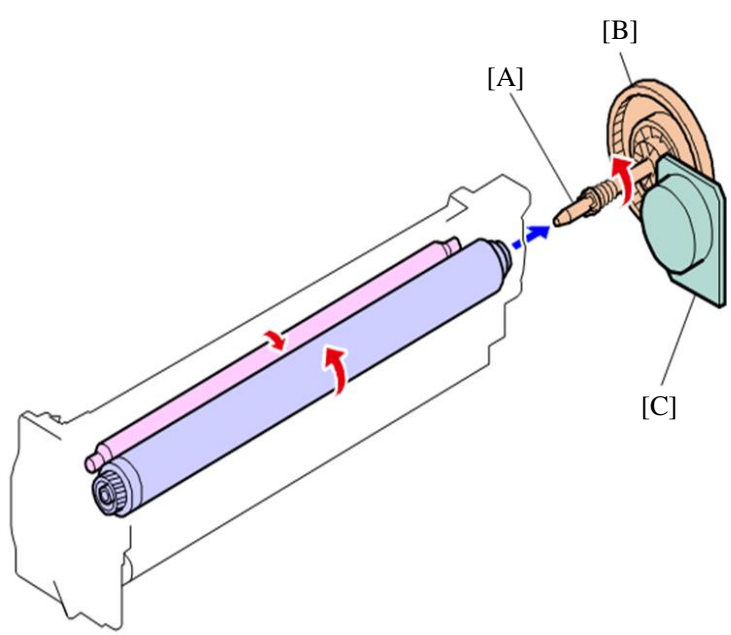

Fig. 7: Shaft attach to motor by coupling and drums are mounting on the shaft

A temperature sensor will use to operate the motor and it will also control the motor movement When temperature will exceed from 35 the sensor will operate the motor and umbrella will open. Similarly, vice versa.

Electrical energy will be given to the motor through battery and this will be a dry battery charged by solar panel. Solar panel will be placed at the roof of the Mosque so that sunlight can directly act on it. At the last before starting the practical work we will make a prototype for illustration according to the methodology given below.

\section{Drum Drive Mechanism}

A drum drive mechanism is a motor drive enclosed within a steel shell providing a single component driving pulley for conveyor belts.

Advantages of drum drive system over a pulley are as following (Carlisle, 2004):

- The large crown angle provides superior belt tracking capabilities

- True concentric machining provides maximum contact with the belt

- Consistent belt content discharge

- Less deflection of shaft

- less stress on the bearings

- The thick pulley will absorb more stress

\section{Carbon Steel Wires}

These wires have a very high tensile strength and flexibility and can increase the strength of any structure up to the desire limit. These wires can bear stress up to a high frequency and are available in circular section or flexible metal rod. Such wires are also used to carry 
electrical loads or electrical and telecommunications signals. The wires are usually constructed by drawing the metal through a hole in a die or pull-out pan. Wire curtains come in standard size, as expressed depending on the gauge number. The word 'wire' is also used with great care in referring to a large number of such fibers, such as in the "bulk wire", which is properly called a wire rope for a mechanic, or a cable in electricity (Nelson et al., 2006). These wires are shown in Fig. 8.

After that a suitable sheet will be selected according to the weather conditions of the region. Material of the sheet will be nylon taffeta because it is smooth, fine, soft and have quick-drying properties. Here are some properties of nylon taffeta sheet given below:

- Nylon taffeta fabric is a lightweight lining material made out of synthetic nylon fibers

- Material: $100 \%$ Nylon Taffeta Fabric

- Width: 57/58', 57'58'

- Feature: Breathable, Down proof, Waterproof, Windproof

- Yarn count: 40D*40D, 68D*68D

- Density: $128 * 102$

- Weight: 60 gsm, 60 gsm

- Composition: $100 \%$

The absorbance of heat depends upon the color. Darker the color more will be the heat absorbed by the umbrella so we select green color because this color filters some extra blue content in sunlight and reduces brilliance. The intensity of green color is $530 \mathrm{~nm}$ which is away from the range harmful for eyes (415-455 nm).

After this a shaft will attach on the roof of the Mosque. The shaft will act like a continuous beam supported by two ball bearings and coupled to a DC motor.

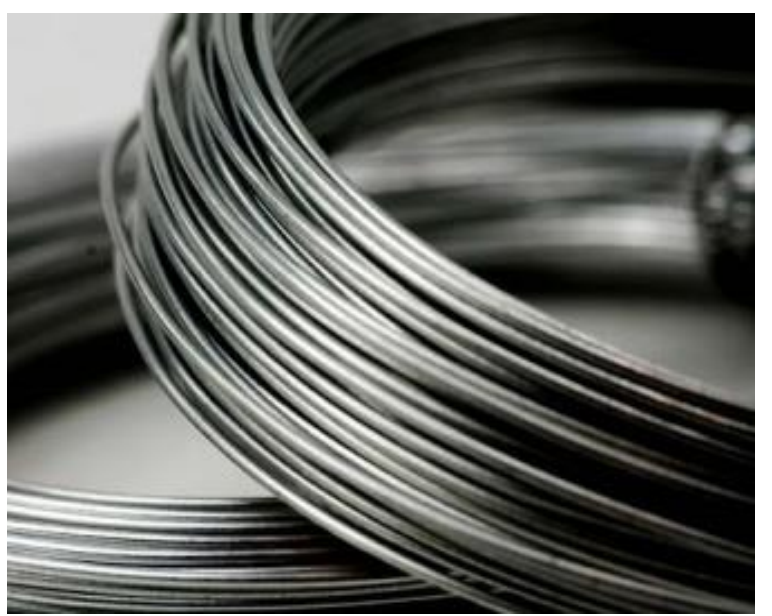

Fig. 8: It is a stainless steel; in this carbon steel may include alloy steels

\section{Components}

\section{Motor and Coupling}

In our project, DC motor is used to provide the necessary rotational motion to the shaft because they have higher starting torque, quick starting and stopping, reversing, variable speeds with easier and cheaper voltage control. Three types of motors generally used are direct current motors, servos and stepper.

The Direct Current (DC) motors are fast, continuous rotating used for anything that needs to be rotate at high rpm for example car tires, fans etc. Servo motors are fast, high torque and rotate accurately within a limited angle designed for robotic arms/legs or cycle control etc. Slow-moving steppers motors have more direct rotation, easier setup and control. Advantage of DC motors over servo motors is control in temporary management. These motors are designed for 3D printers and similar devices where the position is to be located.

The correct motor can be selected based on the specific details. Along with these specifications motor for this project must have some extra characteristics:

- $\quad$ Low voltage (less than 8.4 volts)

- Low amperes (less than $1.0 \mathrm{amp}$ )

- Low cost (less than $15000 \mathrm{Rs}$ )

- $\quad$ Light weight (less than $70 \mathrm{~kg}$ )

- High initial torque (higher than $18.60 \mathrm{~N}-\mathrm{m}$ )

Precise, controllable and resist against any type of weather (Table 1).

\section{Spiral Springs}

An alternative of motors is torsional spiral spring used for folding and unfolding applications of fabric sheets although it operates manually but by using accurate design considerations desirable outcomes can be gotten. A torsional spiral spring is a spring that works by twisting its end along its axis that is a flexible elastic object that stores mechanical energy when it is twisted. The limitation or disadvantage of this mechanism is that it can only be used for manual transmission. Coupling has been used to transmit the torque of motor to the shaft. Rigid coupling is used to connect two shafts in perfect alignments or it is used when axis of two shafts are in same line. Sleeve or muff coupling is the simplest type of rigid coupling so it is more convenient to use this coupling.

Table 1: Permanent DC motor

\begin{tabular}{lll}
\hline Sr. no & Properties & Values \\
\hline 1 & Voltage & $12 / 24 \mathrm{~V}$ \\
2 & Current & $0.5 \mathrm{~A}$ \\
3 & RPM & 90 \\
4 & Power & $220 \mathrm{~W}$ \\
\hline
\end{tabular}




\section{Sleeve or Muff Coupling}

It consists of a hollow sleeve or cylinder made of mild steel or cast iron. This type of coupling is like a box (also called sleeve) and the shafts to be connected are enclosed in this box. The sleeve is like a pipe and the inside diameter of the sleeve is precisely equal to the diameters of the shafts to be connected. Inside keyways are also present in the sleeve so that torque can be transmitted and relative motion can be controlled between the shafts and sleeve. Normally both shafts are connected by means of a Gib head key because this key can easily be attach and removed due to its head (Fig. 9).

\section{Block Bearing}

Bearing is always used for supporting purposes. It provides grip to the rotating shaft. It is mounted on a parallel shaft and perpendicular to the center line of rotating shaft. In our project we have used 6310 number bearing. This bearing is self-aligning pillow block bearing, we can adjust or replace the bearing easily. The bearing has a wide inner ring with set screws for attaching to the shaft (Yassi et al., 2001).

\section{Water Sensor}

A water detector is an electronic device designed to detect the presence of water for purposes such as providing timely awareness to allow for water leakage prevention. To detect rain, we used a water drop recognition module. It contains a series of similar cables. When water droplets come in contact with these wires, the rotation terminates and provides a signal to the microcontroller chip (Arduino) to control the flow of motion (Engst et al., 2005) (Fig. 10).

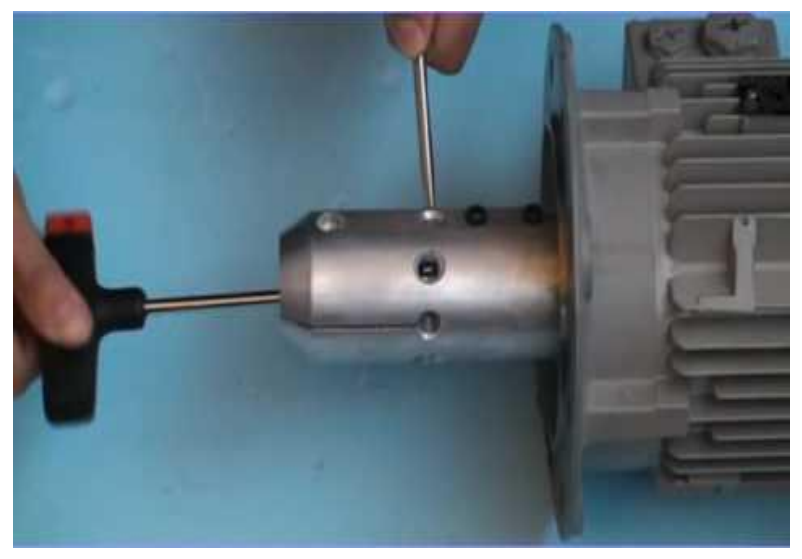

Fig. 9: A coupling is a device used to connect two shafts together at their ends for the purpose of transmitting power

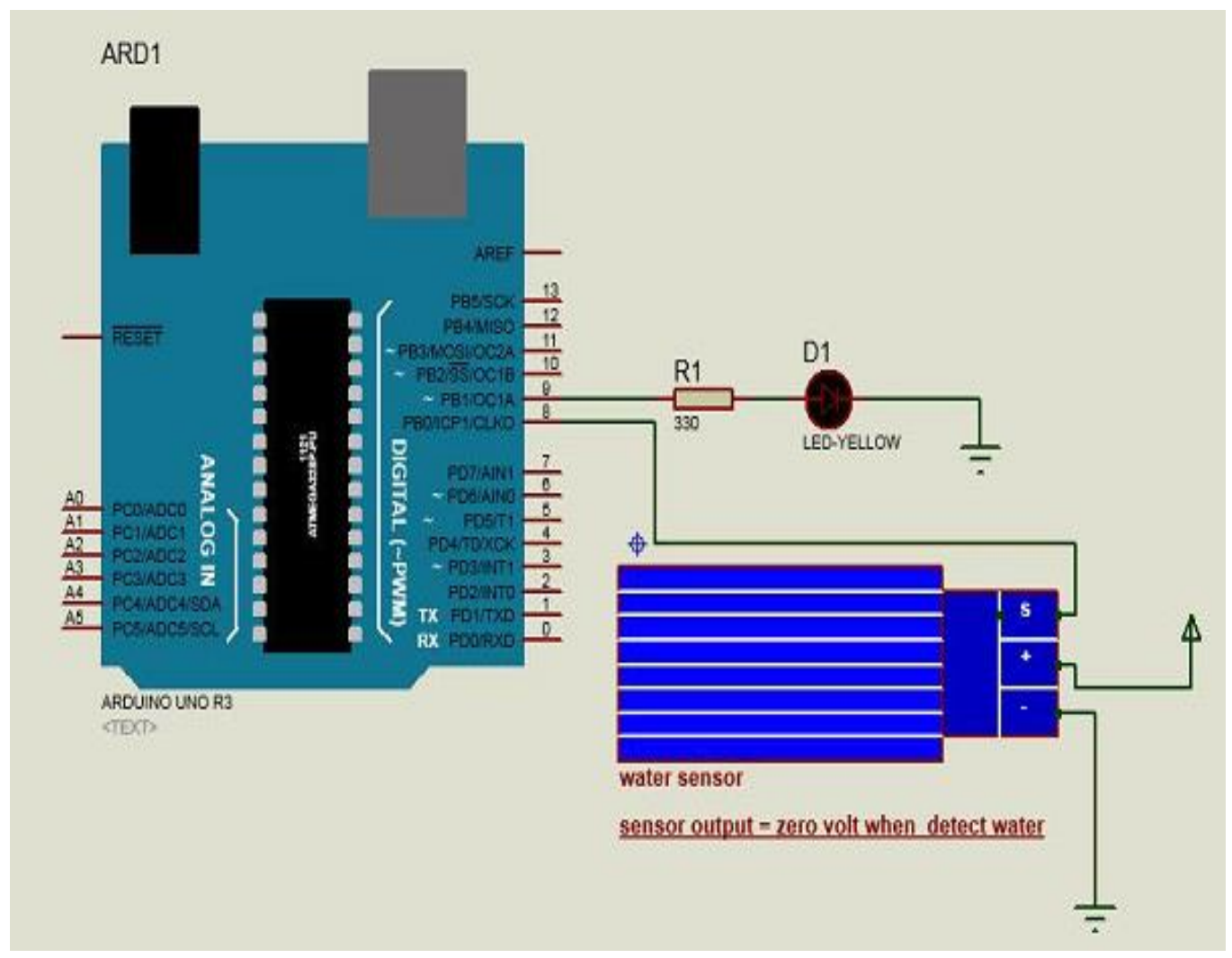

Fig. 10: Water sensor 


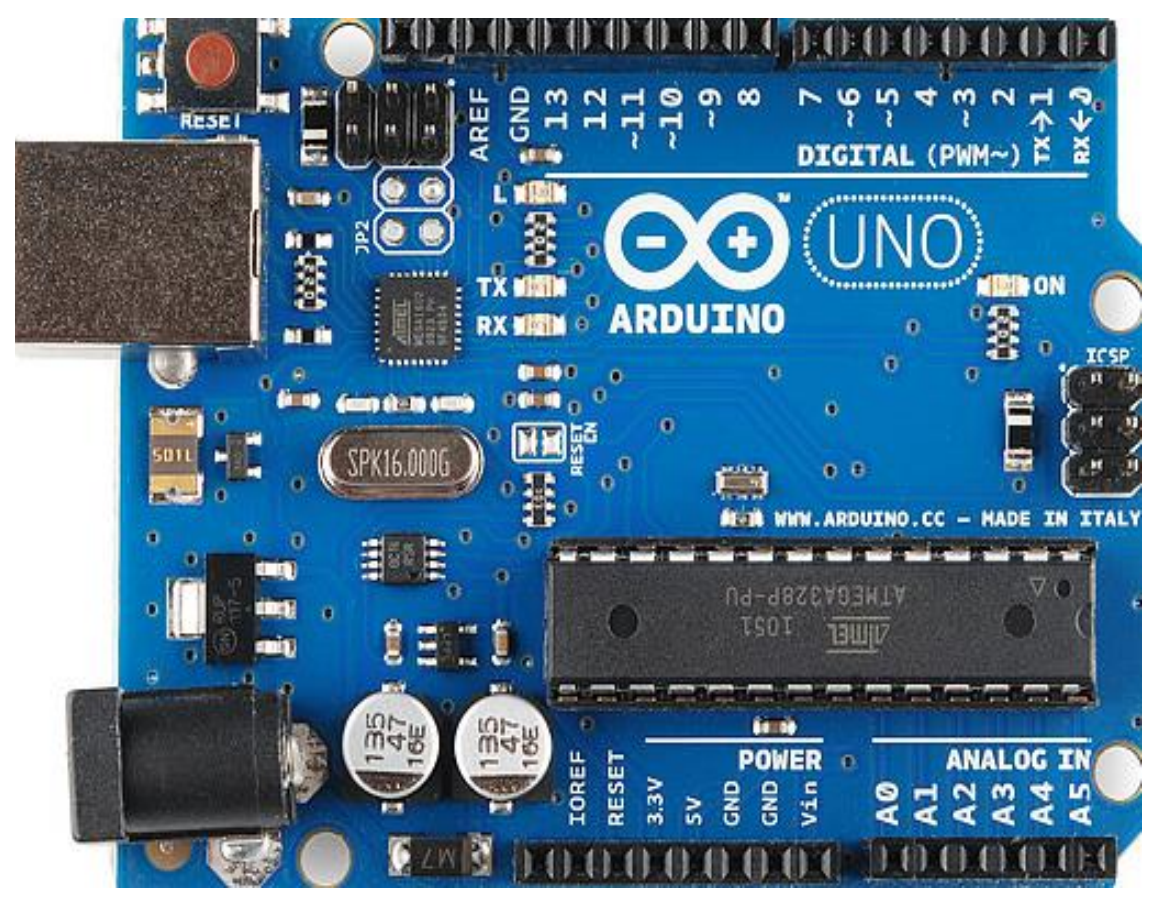

Fig. 11: Arduino

\section{Arduino}

Arduino is an open source electronic source software based on easy-to-use hardware and software. Arduino boards can read input - light sensor, fingerprint, or a message - and then take it out - activate the system, turn on the LED and publish something online. It can control the main circuit board what to do by sending a set of instructions to the microcontroller on board. To do so we use Arduino programming language (Wiring-based) and Arduino Software (IDE), based on Analyzing (Fig. 11).

Over the years Arduino has been the central unit of thousands the electronics and robotics projects, from everyday objects to sophisticated scientific tools. A global community of practitioners - students, programmers and professionals - have gathered in this open source forum over the last few years. It provides incredible amount of information and a great help for professional automated projects.

\section{Motor Driver Integrated Circuit (L293D)}

The motor driver is an integrated circuit chip commonly used to control motors in autonomous robots. The motor driver acts as a link between the Arduino and the motors. ICs are widely used by motorists from L293 series such as L293D, L293NE, etc. These ICs are designed to control 2 DC motors simultaneously. The L293D has a dual H-bridge. The H-bridge is a very convenient circuit for controlling low current rates so the IC driver only drives the L293D. The L293D has 16 pins (Hui et al., 2001) (Fig. 12).

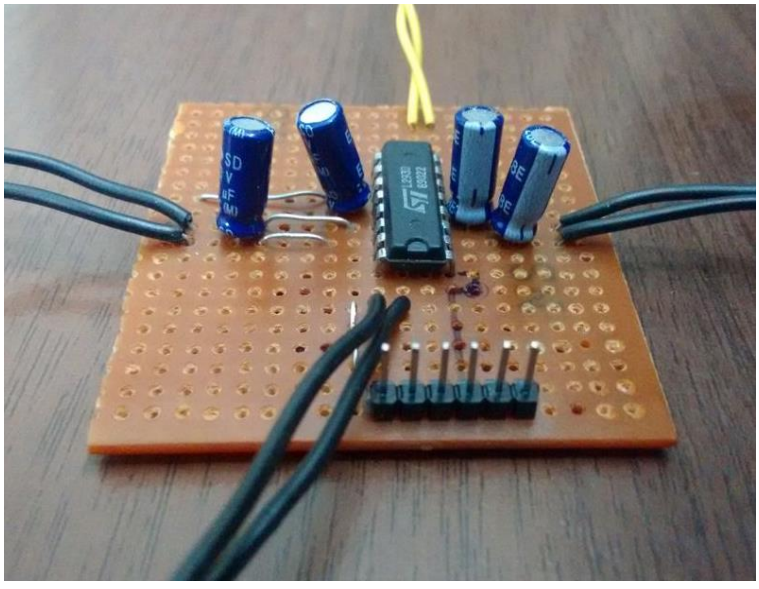

Fig. 12: Integrated circuit

\section{Movement of Umbrella Frame}

It operates both manually and automatically. A handle will available on the front wall of RCET Mosque which can provide ease to open umbrella manually. This is the second option to open the umbrella by hand by rotating the handle attaches to the shaft. Automatically it operates by sensing the temperature of the atmosphere and provide signal to the control box. Motor starts by taking the signal from the sensor and this all phenomena is taken and control by Arduino system. Shaft is attaching above the roof of hall. Motor transfer power to the shaft so that shaft rotates and open the umbrella sheet. 


\section{Circuit Diagram}

Motor DCs usually have only two indicators (leads), one positive and one negative. This lead is very similar to the logical implementation of the strategy. The following table controls the movement of the motor on the basis of logic insertion. When we connect the two components that lead to the battery, the motor rotates. When you change direction, the motor shaft rotates in reverse direction. To control the spin of a DC motor, without changing the way the connectors connect, you can use a circuit called the $\mathrm{H}-$ Bridge. A H-bridge is an electronic circuit that converts the electric current used in a certain load. It is often used in robots and other systems (Fig. 13 and 14).

\section{CAD Model}

\section{Main Body}

This is the area where we have to put our project. There is shaft, motor and transmission power system on the roof. The pulley system is placed on back (Fig. 15).

\section{Curtain}

The curtain will be used to cover the area. This curtain is of 30 by 30 feet. The curtain contains O-rings which move in guided lines (Fig. 16).

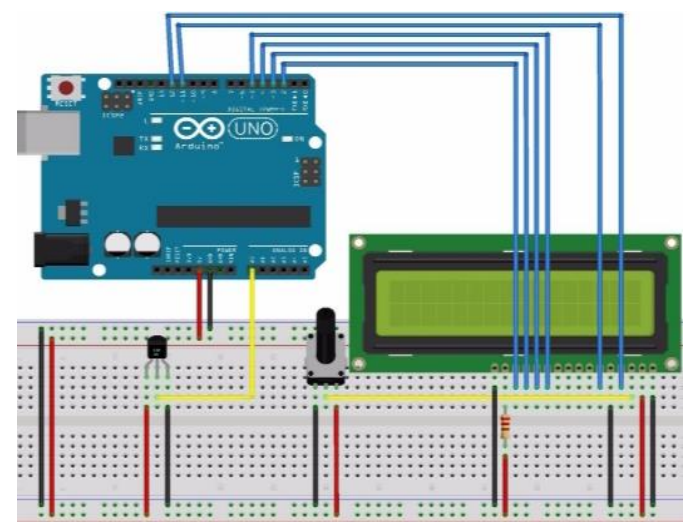

Fig. 13: Circuit diagram

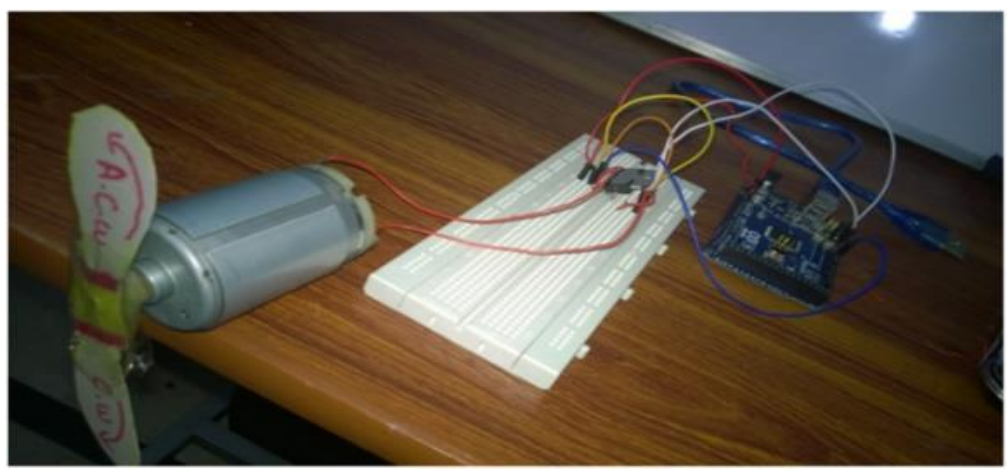

Fig. 14: Whole circuit diagram

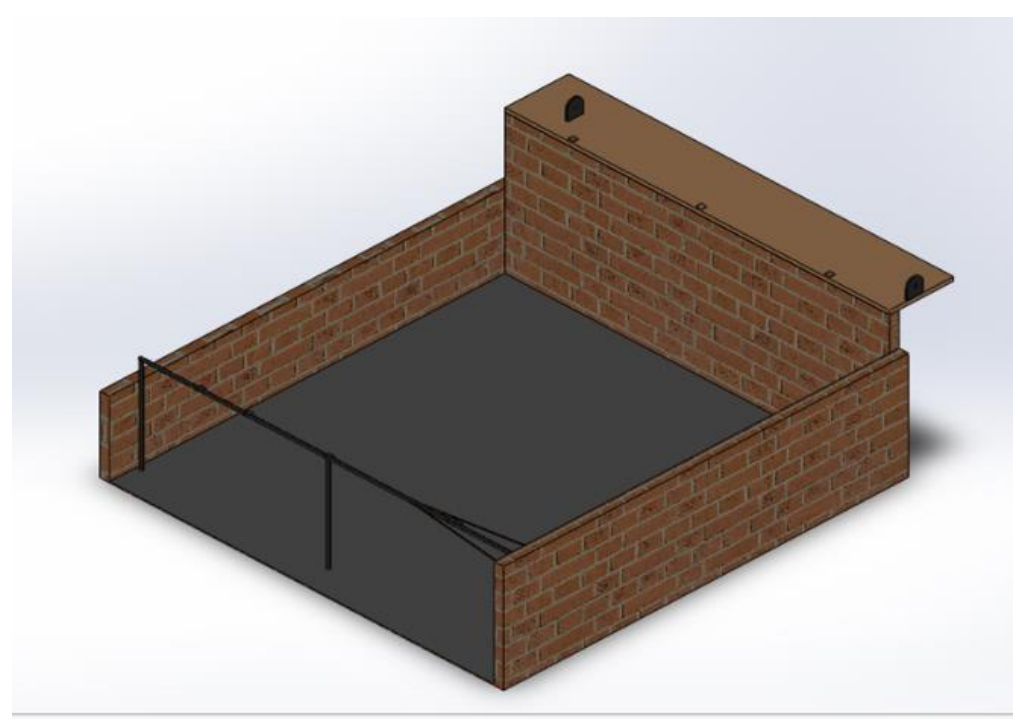

Fig. 15: Isometric view of area 


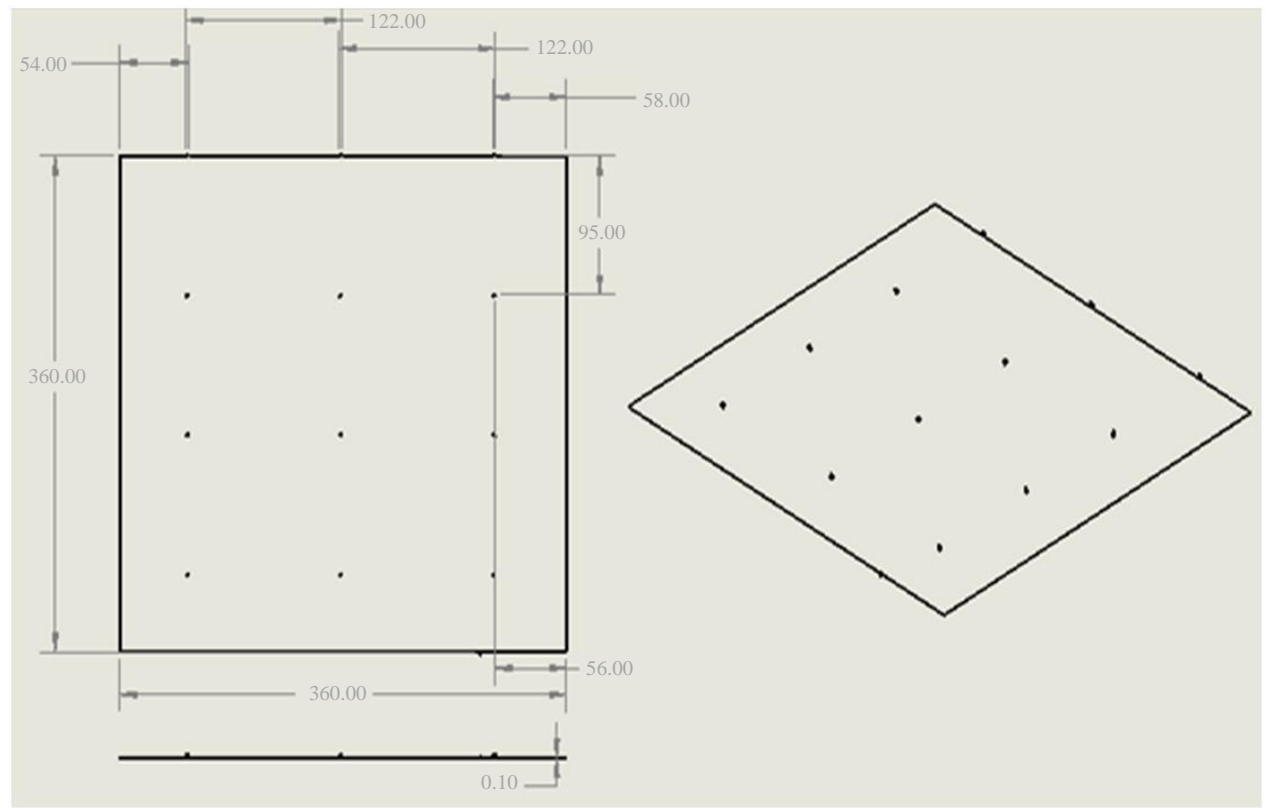

Fig. 16: Dimension of Curtain
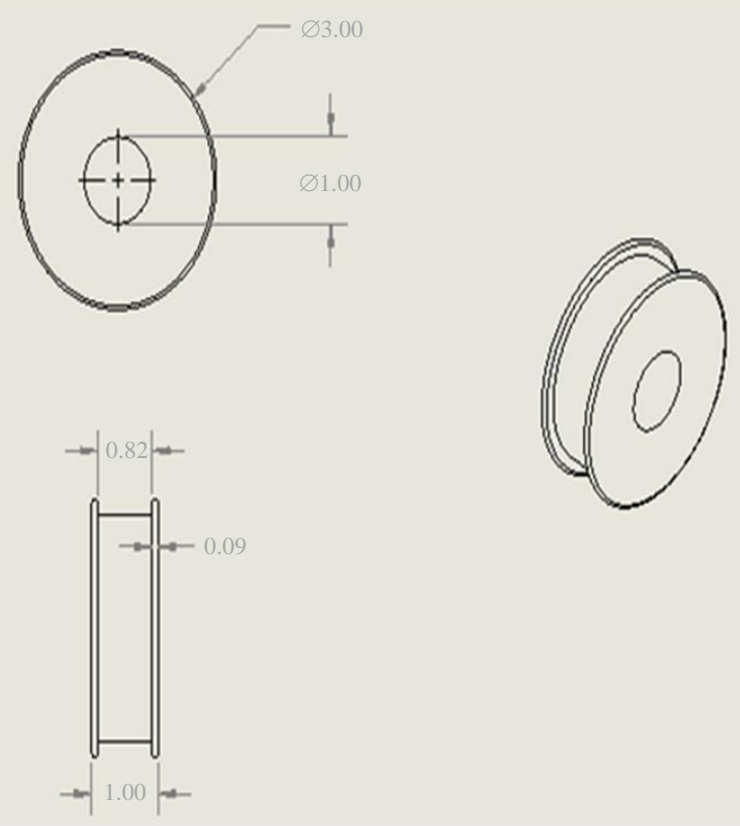

Fig. 17: Dimensions of pulley

\section{Pulley}

Pulley is located at back side on which rope passes through. The pulley is being used with drum for opening and closing of umbrella (Fig. 17 and 18).

\section{Drum}

Drum is installed on shaft which rotates with shaft. The rope passes through drum and goes to the pulley.
The drum drives the rope clockwise for closing the umbrella and anticlockwise for opening the umbrella (Fig. 19).

\section{Drive Unit for Curtain}

Drive unit is used to drive the curtain in forward and backward direction for closing and opening purposes of umbrella. This drive moves in guided lines and one end of curtain is attached with drive unit (Fig. 20). 


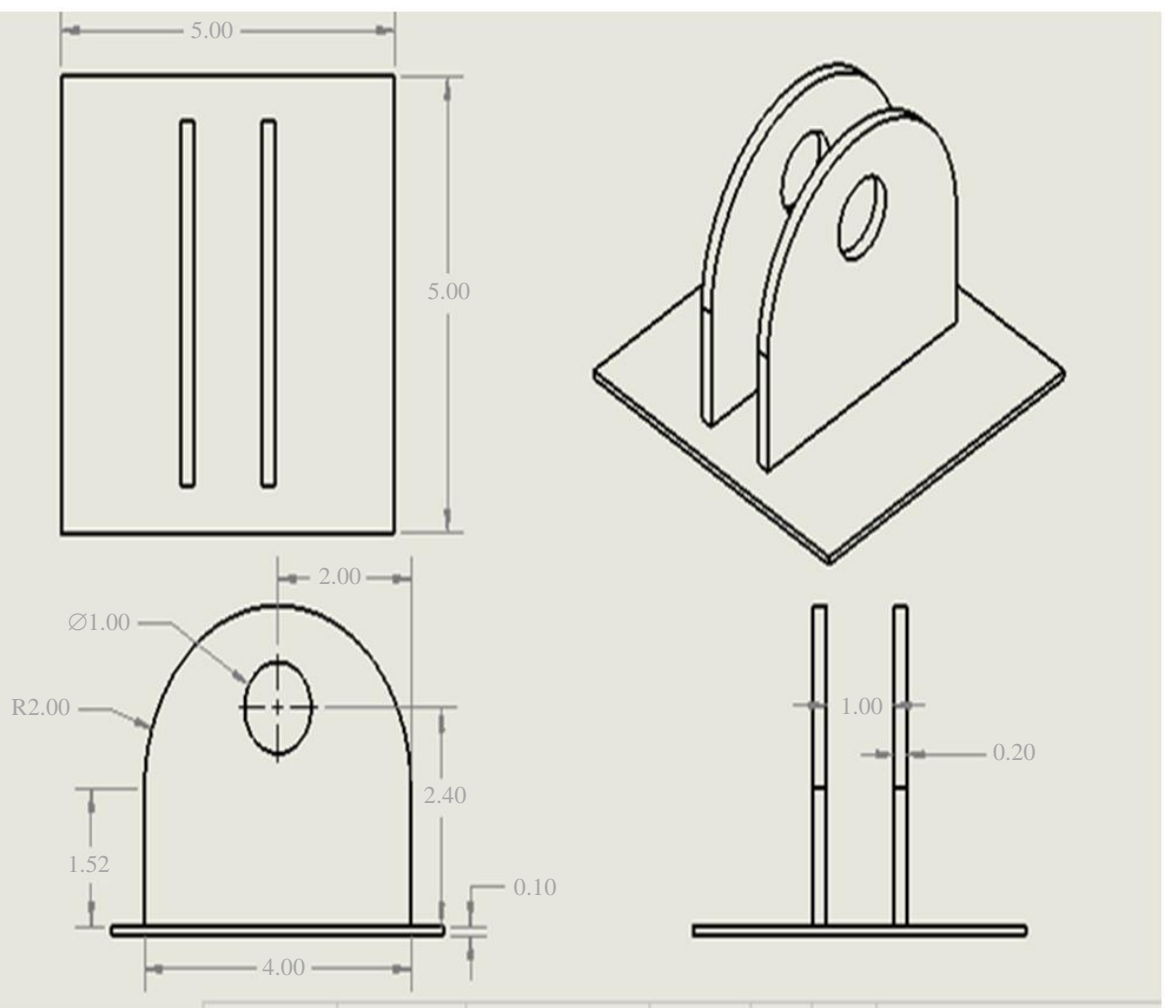

Fig. 18: Dimensions of pulley support
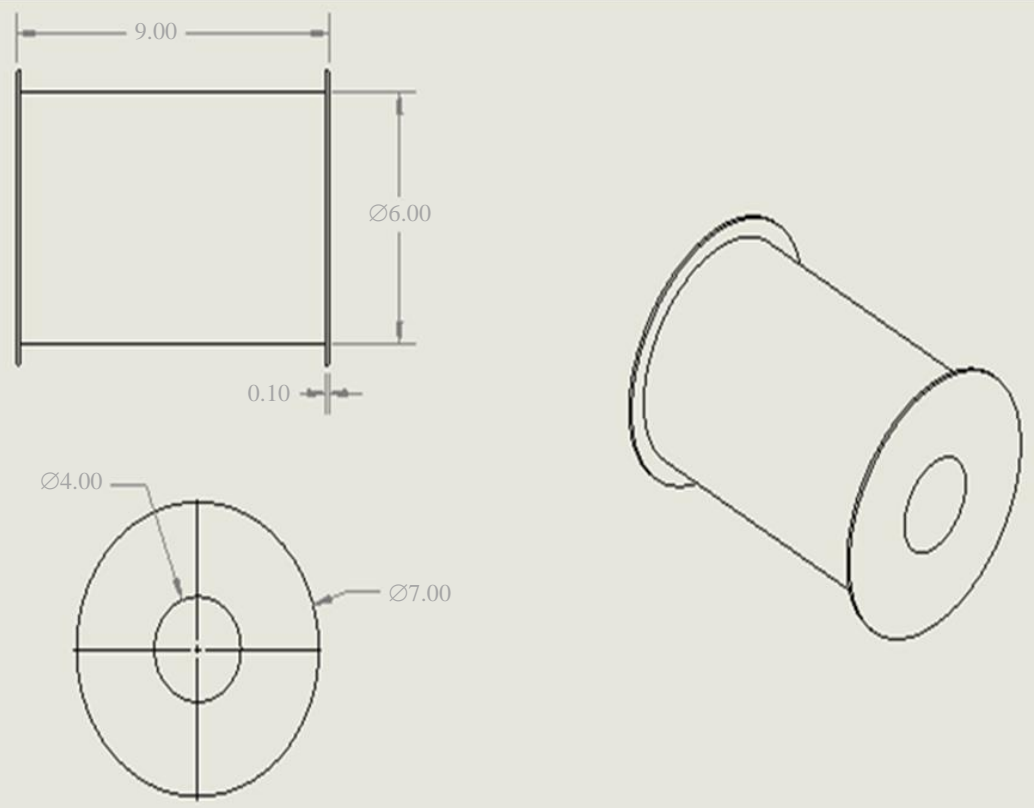

Fig. 19: Dimensions of drum

\section{Shaft}

Shaft is being used to drive the drum which is installed on the shaft. Shaft is coupled with motor when motor rotates clockwise; it starts to rotate in that direction. When motor rotates anticlockwise, it starts to rotate in anticlockwise direction; hence drum changes its rotation with shaft. The diameter of shaft is 4 inches (Fig. 21). 
Meher Dev Gudela et al. / Journal of Mechatronics and Robotics 2020, Volume 4: 191.210

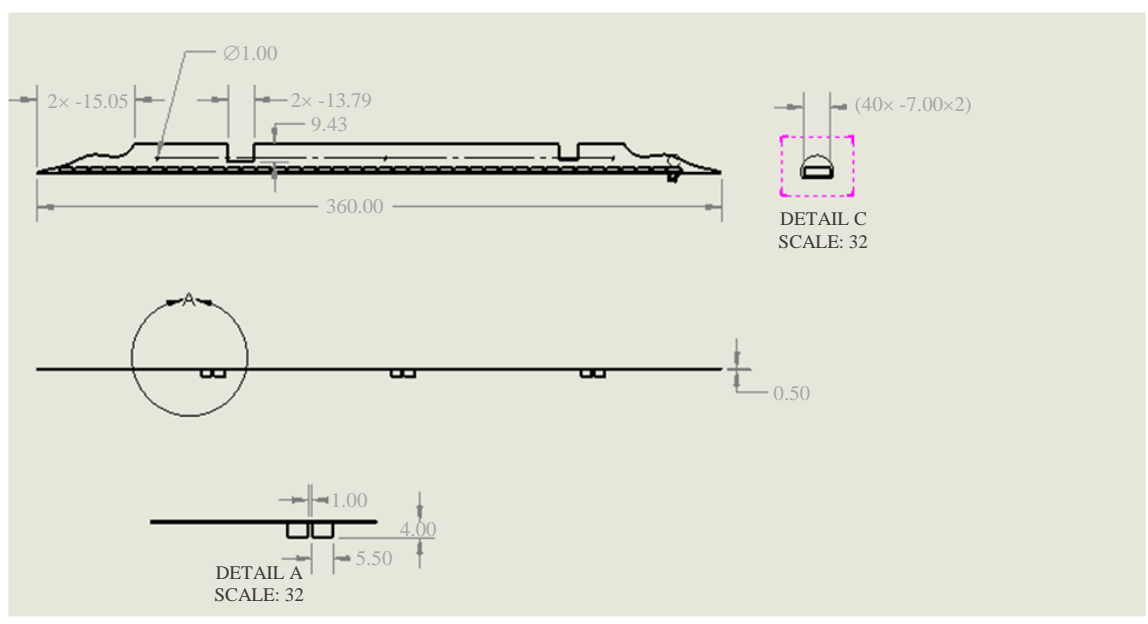

Fig. 20: Dimensions for drive unit

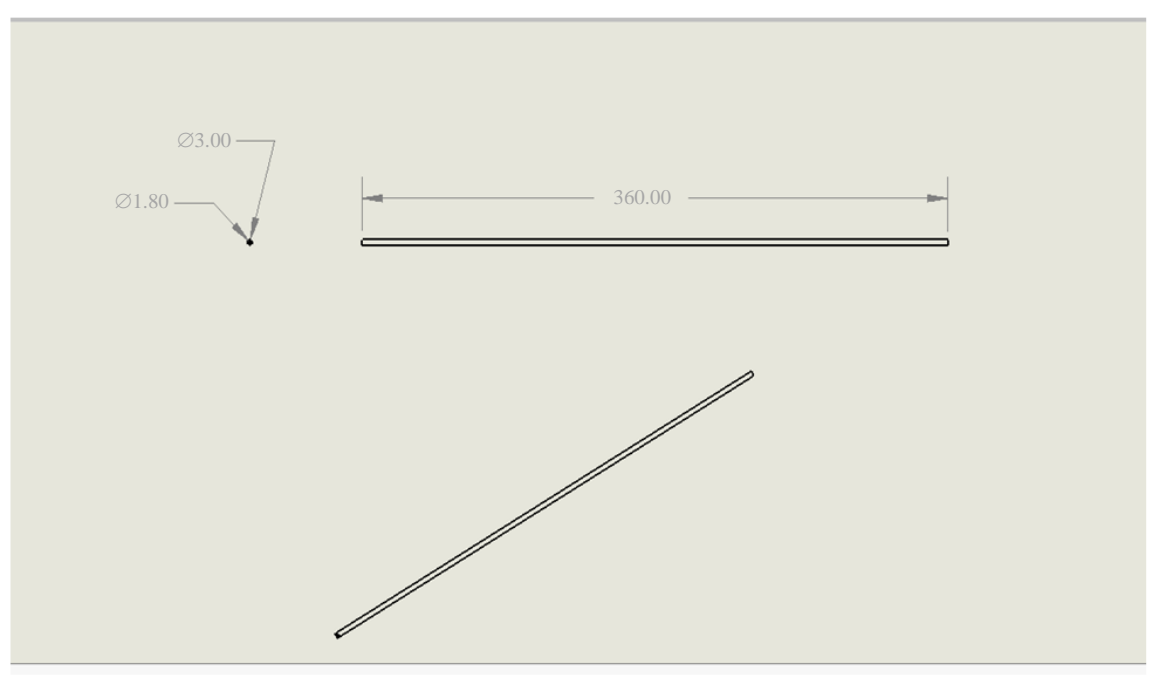

Fig. 21: Dimensions of Shaft

Assembly (Fig. 22)

Fig. 22: Final assembly 


\section{Calculations}

Using SI units in calculation (Fig. 23).

Dia of pulley $=3$ inch $=0.0762 \mathrm{~m}$

Dia of drum $=6$ inch $=0.1524 \mathrm{~m}$

Mass of sheet $=35 \mathrm{~kg}$

$5 \mathrm{~kg}$ mass due to rain/dust

Total $=35+5=40 \mathrm{~kg}$

$\mathrm{h}=5 \mathrm{ft}=1.5 \mathrm{~m}$

$\theta=10^{\circ}$

To approach B from A the work needed is the combination of $\mathrm{W}_{\mathrm{AC}}+\mathrm{W}_{\mathrm{BC}}$

$\mathrm{W}_{\mathrm{BC}}=\mathrm{mgh}$

$=(40)(10)(1.5)=600 \mathrm{~J}$

$\mathrm{W}_{\mathrm{AC}}=\mathrm{F} \times \mathrm{d}$

Here,

$\mathrm{F}=$ frictional force $=\mu \times \mathrm{N}$

$\mathrm{N}=\mathrm{W}=\operatorname{mgcos} 10^{\circ}$

$=40 \times 10 \times 0.984$

$=394 \mathrm{~N}$

Calculation for Total Force Require by the Motor to Pull the Sheet (Fig. 24 and 25)

$\mu$ between mild steel and low carbon steel is 0.5

$\mathrm{F}=\mu \times \mathrm{N}$

$\mathrm{F}=0.5 \times 394$

$\mathrm{F}=197 \mathrm{~N}$

Taking 2 times of the force $\mathrm{F}$ for actual case

$\mathrm{F}_{\mathrm{a}}=2 \times 197=394$

$\mathrm{d}=$ Distance $=9 \mathrm{~m} \quad$ (from fig)

$\mathrm{W}_{\mathrm{AC}}=\mathrm{F} \times \mathrm{d}$

$=394 \times 9$

$\mathrm{W}_{\mathrm{AC}}=3546 \mathrm{~J}$

Power $=\mathrm{W} / \mathrm{t}$

Total work $=\mathrm{W}=\mathrm{W}_{\mathrm{AC}}+\mathrm{W}_{\mathrm{BC}}$

$=3546+600$

$\mathrm{W}=4146 \mathrm{~J}$

$\mathrm{T}=$ time require to open or close umbrella suppose

$1 \mathrm{~min}=60 \mathrm{sec}$

Power $=4146 / 60$

Power $=69$ watt

Mass of pulley $=6 \mathrm{~kg}$

Mass of drum $=8 \mathrm{~kg}$

Weight of drum $=8 \times 10=80 \mathrm{~N}$

Mass of shaft $=17 \mathrm{~kg}$

Diameter of drum $=6$ in

Outer diameter of shaft $=4 \mathrm{inch}=100 \mathrm{~mm}$

Inner diameter of shaft $=45 \mathrm{~mm}$

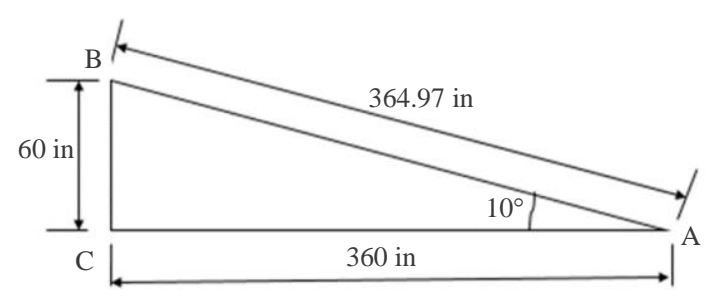

Fig. 23: The slope between drum and pulley

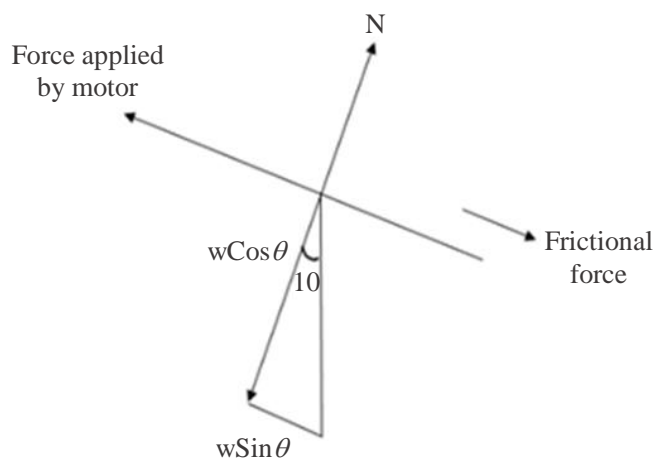

Fig. 24: Resolving components

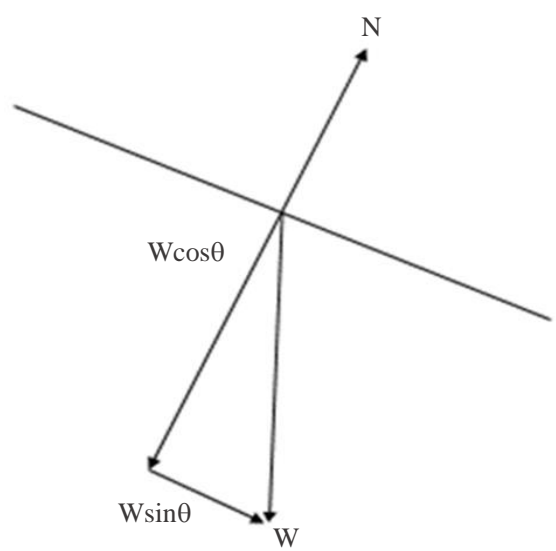

Fig. 25: Resolving components

For dynamic loading motor will pull the sheet towards itself and the require force will be equal to:

$\mathrm{F}=$ force require by motor

$\mathrm{F}_{\mathrm{r}}=$ frictional force

W $\sin \theta=$ component of weight of sheet

$\mathrm{F}=\mathrm{F}_{\mathrm{r}}+\mathrm{w} \sin \theta$

$\mathrm{Fr}=\mu \mathrm{N}$

$\mathrm{m}=35 \mathrm{~kg} \quad(\mathrm{~m}=$ mass of sheet $)$

Weight $=\mathrm{mg}=35 \times 10=350 \mathrm{~N}$

From above Fig

$\mathrm{N}=\mathrm{mg} \cos \theta$ 
$\Theta=10^{\circ}$

$\mathrm{N}=35 \times 10 \times \cos 10^{\circ}$

$\mathrm{F}_{\mathrm{r}}=\mu \times 35 \times 10 \times \cos 10^{\circ}$

$\mu=$ coefficient of friction between mild steel and low carbon steel. There is a sliding contact between ring and steel wires. Material of rings is M.S and steel wire is low carbon steel:

$\mu=0.5$

$\mathrm{F}_{\mathrm{r}}=172 \mathrm{~N}$

$\mathrm{F}=\mathrm{F}_{\mathrm{r}}+\mathrm{Mg} \sin \theta$

$\mathrm{M}=$ mass of sheet + mass of shaft + mass of 2 drums + mass of pulley

$\mathrm{M}=35+17+16+6=74 \mathrm{~kg}$

$=172+(74)(10) \sin \left(10^{\circ}\right)$

$\mathrm{F}=172+129$

$\mathrm{F}=301 \mathrm{~N}$

Force require by motor $=2 \times \mathrm{F}=602 \mathrm{~N}$ (in actual case)

$\mathrm{F}_{\mathrm{a}}=602 \mathrm{~N}$

$\mathrm{T}=\mathrm{F}_{\mathrm{a}} \times \mathrm{r}($ radius of shaft $=0.0381 \mathrm{~m})$

$\mathrm{P}=\frac{2 \pi N T}{60}=\frac{2 \pi N \times F a \times r}{60}=\frac{2 \pi \times 90 \times 602 \times 0.0381}{60}=220$

watt (at $90 \mathrm{rpm})$

Calculation of Net Force Acting on Shaft in Downward Direction

When dynamic load will apply on shaft force $\mathrm{F}$ will resolve into two components (Fig. 26)

$F_{\text {net }}=$ weight of drums + weight of shaft $+F \sin \theta+$ weight of pulley

$\mathrm{F} \sin \theta=602 \times \sin 10^{\circ}$

$=105 \mathrm{~N}$

Weight of shaft $=17 \times 10=170 \mathrm{~N}$

Weight of drums $=2 \times 8 \times 10=160 \mathrm{~N}($ no of drums $=2)$
Weight of pulley $=6 \times 10=60 \mathrm{~N}$

Net force in downward $=F_{\text {net }}=105+170+160+60$

$\mathrm{F}_{\text {net }}=495 \mathrm{~N}$

\section{Design for Shaft (Fig. 27)}

Calculating reaction forces $\mathrm{R}_{\mathrm{a}}$ and $\mathrm{R}_{\mathrm{f}}$ and using SI units $\Sigma M b=0$ (taking clockwise moments +ve and anti clockwise -ve)

$-60(0.1524)-80(2.74)+105(4.27)+80(5.79)-R_{f}(8.53)$ $=0$

$\mathrm{R}_{\mathrm{f}}=131.5 \mathrm{~N}$

$\Sigma F=0$ (upward force + ve \& downward force -ve) $-60-80-105+131.5+\mathrm{R}_{\mathrm{b}}=0$

$\mathrm{R}_{\mathrm{b}}=193.5 \mathrm{~N}$

Calculating moments at all points $\mathrm{M}_{\mathrm{A}}=0$ (no force before A point) (taking clockwise moments +ve and anti-clockwise -ve) $\mathrm{M}_{\mathbf{B}}=-60(0.1524)=-9.144 \mathrm{Nm}$ $\mathrm{M}_{\mathrm{c}}=193.5(2.74)-60(2.9)=356.19 \mathrm{Nm}$

$\mathrm{M}_{\mathrm{D}}=\mathrm{R}_{\mathrm{b}}(4.2)-80(1.524)-60(4.42)$ $=193.5$ (4.2) - 80(1.524) $-60(4.42)$

$\mathrm{M}_{\mathrm{D}}=439.125 \mathrm{Nm}$

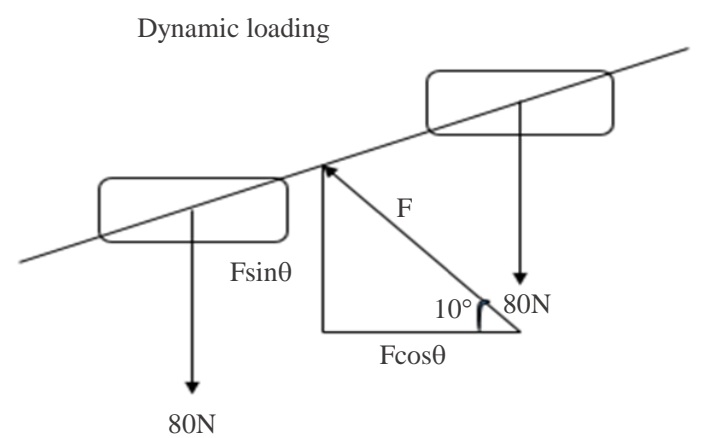

Fig. 26: Resolving components

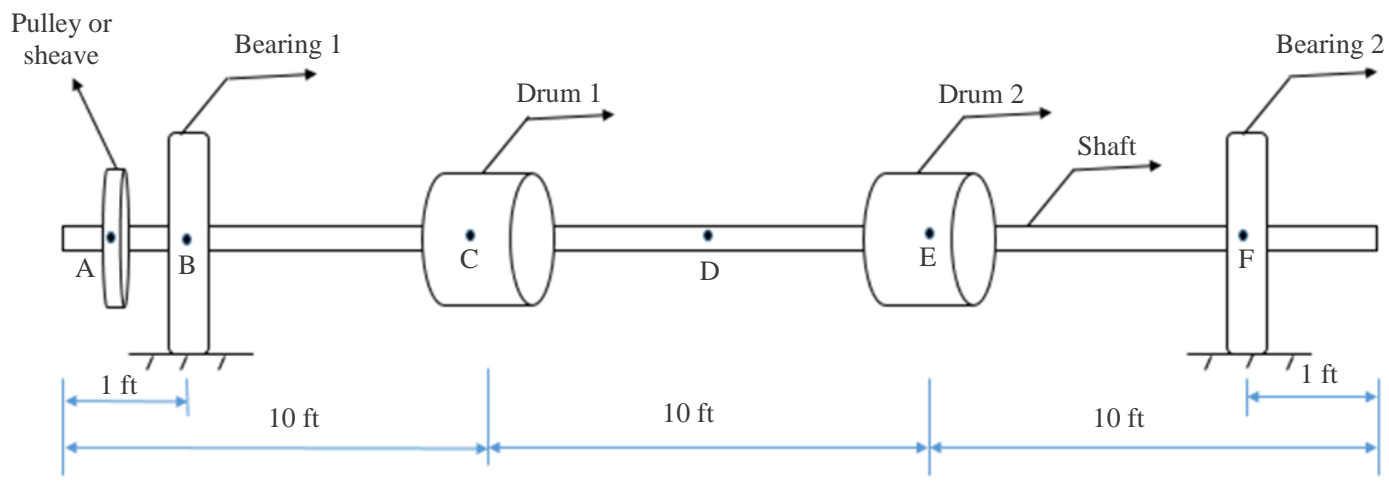

Fig. 27: Shaft 
$\mathrm{M}_{\mathrm{E}}=\mathrm{R}_{\mathrm{b}}(5.79)-60(5.94)-105(1.524)-80(3.048)$

$=193.5(5.79)-60(5.94)-105(1.524)-80(3.048)$

$360.105 \mathrm{Nm}$

$\mathrm{M}_{\mathrm{F}}=\mathrm{R}_{\mathrm{b}}(8.53)-60(8.7)-105(4.27)-80(2.74)-80(5.79)$

$\mathrm{M}_{\mathrm{F}}=-2.195$

Now the highest moment is at point $\mathrm{D}=439.125 \mathrm{Nm}$

Applying flexural equation at point $\mathrm{D}$ to calculate maximum bending strength

$$
\frac{M}{I}=\frac{S b}{y}
$$

$\mathrm{M}=$ bending moment

$\mathrm{y}=$ vertical distance away from the neutral axis $=\mathrm{d}_{\mathrm{o}} / 2=$ $3 / 2=1.5 \mathrm{in}$

$\mathrm{S}_{\mathrm{b}}=$ max bending strength

$I=$ moment of inertia around the neutral axis $=\frac{\pi}{64}$ $\left(\mathrm{do}^{4}-\mathrm{di}^{4}\right)$

$=\frac{\pi}{64}\left(3^{4}-1.8^{4}\right)=3.46 \mathrm{in}^{4}$

Taking $\mathrm{M}=\mathrm{M}_{\mathrm{D}}=439.125 \mathrm{Nm}=3886.5 \mathrm{lb}$-in

$\mathrm{S}_{\mathrm{b}}=\frac{3886.5 \times 1.5}{3.46}=1685 \mathrm{psi}$

Material of shaft is cold rolled mild steel having following mechanical properties.

$\mathrm{S}_{\mathrm{ut}}=58000 \mathrm{psi}$

$\mathrm{S}_{\mathrm{y}}=53700 \mathrm{psi}$

Uncorrected endurance strength $=\mathrm{S}_{\mathrm{e}}{ }^{\prime}=0.5\left(\mathrm{~S}_{\mathrm{ut}}\right)$

$=0.5(58000)=29000 \mathrm{psi}$
Corrected endurance limit $=\mathrm{S}_{\mathrm{e}}=\mathrm{C}_{\text {load }} \mathrm{C}_{\text {size }} \mathrm{C}_{\text {surf }} \mathrm{C}_{\text {temp }} \mathrm{C}_{\text {reli }} \mathrm{S}_{\mathrm{e}}{ }^{\prime}$

$\mathrm{C}_{\text {load }}=1$ (for bending and torsion)

$\mathrm{C}_{\text {size }}=1$ (assumption)

$\mathrm{C}_{\text {surf }}=0.84$ (for cold rolled machine finished shaft)

$\mathrm{C}_{\text {temp }}=1$ (operating temp $<450^{\circ}$ )

$\mathrm{C}_{\text {reli }}=1$ (for $50 \%$ reliability)

$\mathrm{S}_{\mathrm{e}}=(1)(1)(0.84)(1)(1)(29000)=24360 \mathrm{Psi}$

$\mathrm{K}_{\mathrm{f}}=1+\mathrm{q}(\mathrm{Kt}-1)(\mathrm{q}=0.5, \mathrm{Kt}=3.5$ for bending $)$

$\mathrm{K}_{\mathrm{f}}=2.25$

$\mathrm{K}_{\mathrm{fs}}=1+\mathrm{q}\left(\mathrm{K}_{\mathrm{ts}}-1\right)(\mathrm{q}=0.57, \mathrm{Kts}=2$ for torsion $)$

$\mathrm{K}_{\mathrm{fsm}}=1.57$

Taking $\mathrm{M}_{\mathrm{a}}=$ maximum bending moment $=\mathrm{M}_{\mathrm{D}}=3886.5$ lb-in

$\mathrm{T}_{\mathrm{m}}=\mathrm{F} \times \mathrm{r}$

Where $\mathrm{F}=$ force applied by the motor $=602 \mathrm{~N}=$ $135.335 \mathrm{lb}$

$\mathrm{r}=$ outer radius of shaft $=1.5 \mathrm{in}$

$\mathrm{T}_{\mathrm{m}}=135.335 \times 2=203.0025 \mathrm{lb}$-in

Now using ASME method to calculate factor of safety of shaft:

$d=\left\{\frac{32 N f}{\pi}\left[\left(\frac{K f \times M a}{S f}\right)^{2}+\frac{3}{4}\left(\frac{K f s m \times T m}{S y}\right)^{2}\right]^{0.5}\right\}^{1 / 3}$

$3=\left\{\frac{32 \times N f}{\pi}\left[\left(\frac{2.25 \times 3886.5}{243.60}\right)^{2}+\frac{3}{4}\left(\frac{1.57 \times 203.0025}{53700}\right)^{2}\right]^{0.5}\right\}^{1 / 3}$

$\mathrm{N}_{\mathrm{f}}=7.38$

So, design is safe as $\mathrm{N}_{\mathrm{f}}>1$ shaft is safe having outside diameter of $3 \mathrm{in}$.

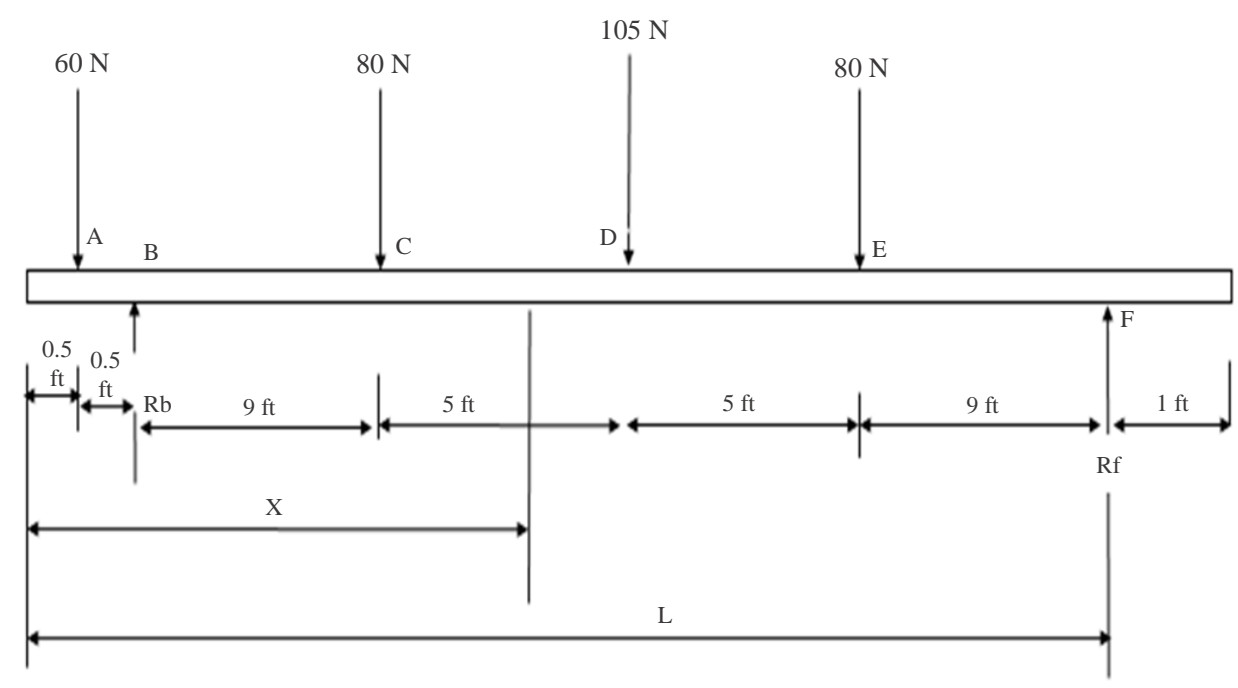

Fig. 28: Deflection 


\section{Deflection in Shaft}

Applying equation of elastic curve EI $\mathrm{d}^{2} \mathrm{y} / \mathrm{dx}^{2}=\mathrm{M}(\mathrm{x})$.

Maximum moment is at point $\mathrm{D}$ so finding deflection at point $\mathrm{D}$. To find $\mathrm{M}(\mathrm{x})$ we have to consider a distance before the point on which we want to find the deflection as shown in Fig. 28.

Performing above calclation in SI units

$M(x)=-60(x-0.15)-80(x-3)+R_{b}(x-0.3)$

$=-60 \mathrm{x}+9-80 \mathrm{x}+240+\mathrm{R}_{\mathrm{b}} \mathrm{x}-\mathrm{R}_{\mathrm{b}} 0.3$

$=-60 x+9-80 x+240+(193.5) x-(193.5) 0.3$

$=190.95+53.5 \mathrm{x}$

EI $d^{2} y / d x^{2}=190.95+53.5 x$

EI dy/dx $=190.95 \mathrm{x}+53.5 \mathrm{x}^{2} / 2+\mathrm{C}_{1}$ (1) (performing $1 \mathrm{st}$ integration)

EI $\mathrm{y}=190.95 \mathrm{x}^{2} / 2+53.5 \mathrm{x}^{3} / 6+\mathrm{C}_{1} \mathrm{x}+\mathrm{C}_{2}$ (2) (performing 2nd integration)

At $\mathrm{x}=0, \mathrm{y}=0$ so applying this condition on (2) $\mathrm{C}_{2}=0$

At $\mathrm{x}=\mathrm{L}, \mathrm{y}=0$ apply on eq2 $\mathrm{C}_{1}=-1239$

where $\mathrm{x}=\mathrm{L}=$ distance between two bearing supports $=$ $28 \mathrm{ft}=8.5 \mathrm{~m}$

Finding the deflection at point $\mathrm{D}$ so using $\mathrm{x}=4.6 \mathrm{~m}, \mathrm{C}_{2}=$ $0, \mathrm{C}_{1}=-1239, \mathrm{E}=186 \mathrm{Gpa}, \mathrm{I}=1.35 \mathrm{E}-6 \mathrm{~m}^{4}$ in (2) $\mathrm{y}=0.01 \mathrm{~m}=0.39$ in

\section{Calculation for Limits of Save Cycles of Revolution}

In above calculations units for stress are Mpa and diameters in $\mathrm{mm}$ :

Using eq(6.5 a from book)

Sè $\approx 0.5$ Sut

$=0.5(58000)$

Sè $=29000$ psi

The part is larger than the test specimen and is not in square cross section so equivalent

Diameter be considered as internal dia of hollow shaft.

$D_{\text {equivalnt }}=45 \mathrm{~mm}$

$\mathrm{C}_{\text {size }}=0.869 \times(45)^{-0.097}$

$\mathrm{C}_{\text {size }}=0.6$

$\mathrm{C}_{\text {surf }}=\mathrm{A} \mathrm{Sut}^{\mathrm{b}}$

A and $\mathrm{b}$ for cold rolled shaft

$\mathrm{A}=4.51 \mathrm{~b}=-0.265$

$\mathrm{C}_{\text {surf }}=4.51 \times(400)^{-0.265}$

$\mathrm{C}_{\text {surf }}=0.92$

$\mathrm{C}_{\text {Temp }}=1$ (because operating tem $<450^{\circ} \mathrm{C}$
$\mathrm{C}_{\text {reliability }}=0.753$ for $99.9 \%$ reliability

$\mathrm{Se}=\mathrm{C}_{\text {Load }} \mathrm{C}_{\text {Size }} \mathrm{C}_{\text {Surf }} \mathrm{C}_{\text {Temp }} \mathrm{C}_{\text {reliability }}$ Sè

$\mathrm{Se}=(1)(0.6)(0.92)(1)(0.753)(29000)$

Corrected endurance limit $=\mathrm{Se}=12078 \mathrm{psi}$

Estimated strength $=\mathrm{S}_{\mathrm{m}}=(0.90)(58000)(\mathrm{Eq} 6.9)$

$=52200 \mathrm{psi}$

$\mathrm{S}(\mathrm{N})=\mathrm{a} \mathrm{N} \mathrm{N}^{\mathrm{b}} \mathrm{N}=($ Save cycles of revolutions $)$

$\mathrm{b}=-1 / 3 \log \left(\frac{s m}{s e}\right)$

$\mathrm{b}=-1 / 3 \log \left(\frac{52200}{12078}\right)$

$\mathrm{b}=-0.21$

$\log (\mathrm{a})=\log \mathrm{S}_{\mathrm{m}}-3 \mathrm{~b}$

$\mathrm{a}=\log (52200)-3(-0.15)$

$\mathrm{a}=222675$

$\mathrm{S}(\mathrm{N})=\mathrm{a} \mathrm{N}$

Taking $\mathrm{S}(\mathrm{N})=\mathrm{S}_{\mathrm{e}}$

$\mathrm{S}(\mathrm{N})$ can also be taken as Sut or Se when desired rpm output is checked at endurance or maximum tensile strength limit respectively.

$12078=222675 \mathrm{~N}^{-0.15}$

$\mathrm{N}^{-0.21}=\frac{12078}{222675}$

$\mathrm{N}=1.06 \mathrm{E} 6$

So, failure will not occur up to E6 revolutions.

\section{Selection for Ball Bearing}

For $100 \mathrm{~mm}$ bore dia of bearing

Bearing No. is 6310

$\mathrm{C}=10600 \mathrm{lb}$

$\mathrm{C}_{\mathrm{o}}=8150 \mathrm{lb}$

Fatigue life of bearing $=\mathrm{L}_{10}=\left(\frac{c}{p}\right)^{3}$

Where $\mathrm{p}=$ radial force acting on the ball bearing $=\mathrm{F}$ $\sin \theta=602 \times \sin 10=105 \mathrm{~N}$

$=\left(\frac{10600}{105}\right)^{3}$

$\mathrm{L}_{10}=1.03 \mathrm{E} 6$ revolutions

Life of roller bearing with selected failure rate $=L_{p}=K_{R}$ $\mathrm{L}_{10}$

Failure factor $=K_{R}=0.62$ at $5 \%$ failure rate

$\mathrm{L}_{\mathrm{p}}=0.62(23 \mathrm{E} 5)=14.3 \mathrm{E} 5$ revolutions

\section{Analysis}

Ansys develops and markets simulation software for use throughout the product life cycle (25.) Ansys 
analytics software is used to simulate computer models of structural, electronic, or mechanical components for power, durability and heat distribution. Electronics, water flow and other features. Ansys is used to determine how a product will perform in a variety of specific applications, in addition to testing products for building or performing crash tests.
The Ansys Workbench program is one of the main products of Ansys. Significant analysis which is useful in this study are discussed below.

\section{Deformation Analysis}

Total deformation calculated is 0.39 in and obtained from Ansys is 0.15 in (Fig. 29 and 30).

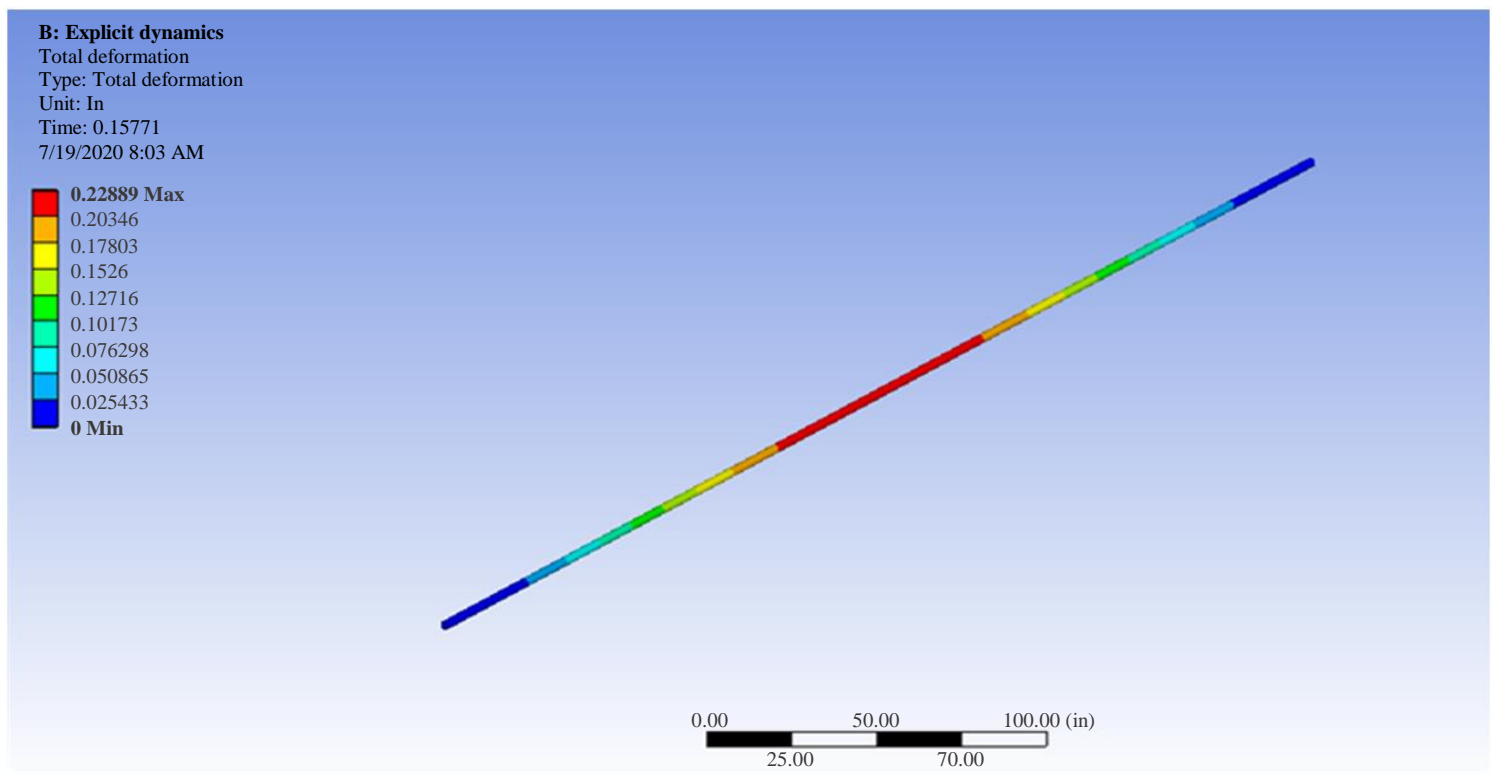

Fig. 29: Total deformation of shaft

\begin{tabular}{|c|c|c|}
\hline Object name & Total deformation & Equivalent stress \\
\hline State & \multicolumn{2}{|c|}{ Solved } \\
\hline \multicolumn{3}{|c|}{ Scope } \\
\hline Scoping method & \multicolumn{2}{|c|}{ Geometry selection } \\
\hline Geometry & \multicolumn{2}{|r|}{ All bodies } \\
\hline \multicolumn{3}{|c|}{ Definition } \\
\hline Type & Total deformation & Equivalent (von-Mises) stress \\
\hline By & \multicolumn{2}{|r|}{ Time } \\
\hline Display time & \multicolumn{2}{|r|}{ Last } \\
\hline Calculate time history & \multicolumn{2}{|r|}{ Yes } \\
\hline \multicolumn{3}{|l|}{ Identifier } \\
\hline Suppressed & \multicolumn{2}{|r|}{ No } \\
\hline \multicolumn{3}{|c|}{ Results } \\
\hline Minimum & 0 in & $0.37319 \mathrm{psi}$ \\
\hline Maximum & 0.22889 in & $2018.4 \mathrm{psi}$ \\
\hline \multicolumn{3}{|c|}{ Information } \\
\hline Time & \multicolumn{2}{|r|}{$3 . s$} \\
\hline Load step & \multicolumn{2}{|r|}{1} \\
\hline Sub step & \multicolumn{2}{|r|}{1} \\
\hline Iteration number & \multicolumn{2}{|r|}{1} \\
\hline \multicolumn{3}{|c|}{ Integration point results } \\
\hline Display option & & Averaged \\
\hline
\end{tabular}

Fig. 30: Table for analysis 


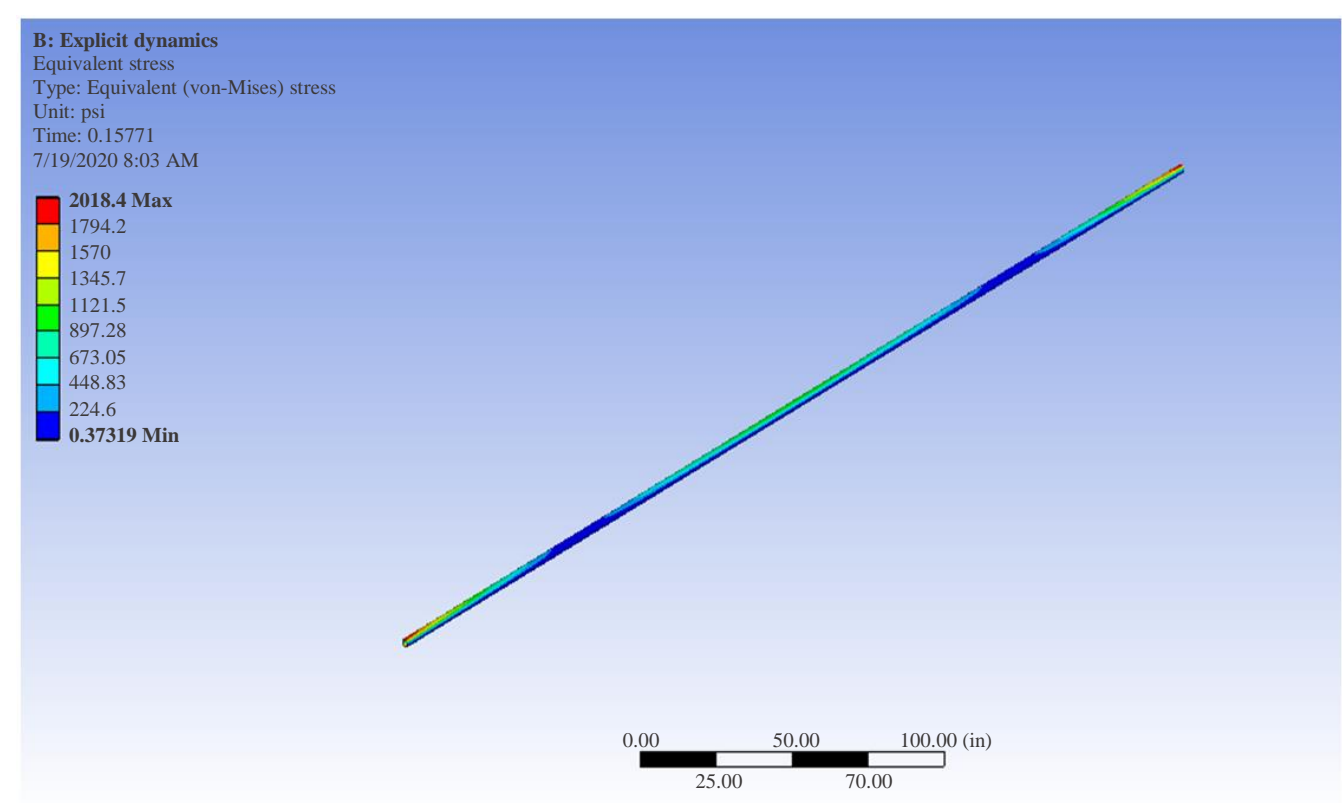

Fig. 31: Resolving components

\begin{tabular}{|c|c|c|}
\hline Object name & Total deformation & Equivalent stress \\
\hline State & \multicolumn{2}{|c|}{ Solved } \\
\hline \multicolumn{3}{|c|}{ Scope } \\
\hline Scoping method & \multicolumn{2}{|c|}{ Geometry selection } \\
\hline Geometry & \multicolumn{2}{|c|}{ All bodies } \\
\hline \multicolumn{3}{|c|}{ Definition } \\
\hline Type & Total deformation & Equivalent (von-Mises) stress \\
\hline By & \multicolumn{2}{|r|}{ Time } \\
\hline Display time & \multicolumn{2}{|r|}{ Last } \\
\hline Calculate time history & \multicolumn{2}{|r|}{ Yes } \\
\hline \multicolumn{3}{|l|}{ Identifier } \\
\hline Suppressed & \multicolumn{2}{|r|}{ No } \\
\hline \multicolumn{3}{|c|}{ Results } \\
\hline Minimum & 0 in & $0.37319 \mathrm{psi}$ \\
\hline Maximum & 0.22889 in & $2018.4 \mathrm{psi}$ \\
\hline \multicolumn{3}{|c|}{ Information } \\
\hline Time & \multicolumn{2}{|r|}{$3 . s$} \\
\hline Load step & \multicolumn{2}{|r|}{1} \\
\hline Sub step & \multicolumn{2}{|r|}{1} \\
\hline Iteration number & \multicolumn{2}{|r|}{1} \\
\hline \multicolumn{3}{|c|}{ Integration point results } \\
\hline Display option & & Averaged \\
\hline
\end{tabular}

Fig. 32: Table for analysis

\section{Stress Analysis}

Stress calculated is 1685 psi and obtained from Ansys is 1909 psi (Fig. 31 and 32).

\section{Results}

\section{Deflection in Shaft}

The maximum deflection calculated on Ansys is 0.23 in and from manual calculation it is 0.39 in. The difference in both results is due to the material properties and approach used. In manual calculation we have applied a differential equation of 2 nd order (equation of elastic curve) and consider the highest value of moment on shaft to calculate the maximum deflection. In Ansys there might be some difference in the approach the software is using for solving the differential equation and how the software consider the sense of the load applying on the shaft.

Another reason due to which results are different is that when we calculate bending moments in a shaft or a 
beam we consider 2D geometry but when we perform an analysis on a simulation software the complete $3 \mathrm{~d}$ model is under consideration. The sense of the applied load on the given geometry can be changed as the load applied in all three axes of the design.

To calculate the maximum deflection in the shaft or beam we take the maximum value of the bending moment which is acting on the beam. After that a point before the max bending moment is selected which is an assumed value. The above point can be selected at any cross section of the beam before the max bending moment point. This distance is taken from the fixed support of the beam and is generally denoted by $x$ (as mentioned in the above calculation). The way which software used might be different for the above considerations so that manual and simulated results can be different.

\section{Stress on Shaft}

The bending stress calculated manually is 1685 psi and obtained from Ansys is 2018.4 psi. The difference in results is due the approach used for calculation. In manual calculation we have applied flexural formula to calculate bending strength in which neutral axis of the shaft requires a great attention whereas the software is considering the complete $3 \mathrm{~d}$ part so the sense is changed because twisting effect also include in the component. When the software takes the whole shaft for analysis then preciseness will increase and definitely, we will get greater value than the actual case.

\section{Safety Factor of Shaft}

The fatigue safety factor calculated manually is 7.38 for shaft but from Ansys it is 15 which is almost 2 times. This difference is quite large. The reason is that in Ansys we have to choose a small analysis time. If we set large analysis time the software takes too much time to solve even sometimes after solution the results are unacceptable. In manual calculation we have set the time $60 \mathrm{sec}$ where as in Ansys it is $3 \mathrm{sec}$ due to hardware limitations of operating system. In manual calculation we have adopted ASME method to calculate factor of safety in which additional modification is considered to specify the full specification of the complete aspect of safety from fatigue under symmetrical loading, using non-statistically significant safety factors (according to load) and fatigue (with emphasis on amplitude). In this approach of design, we assume that the loading has stopped and the combined number of cycles is large enough to assume the maximum fatigue of the cycle. On the other hand, simulation software might be using some other approach to do so.

\section{Conclusion}

After completing our project successfully, we have concluded that our project is a cost-effective way of providing automated shade and shelter from high intensity sunlight and rain. This type of automated umbrella could be widely used for various purposes. It could be installed in large open spaces where shade and shelter are required. Further modifications can be made to get better result. If we use a powerful motor having larger torque with larger umbrella, i.e., café size umbrella, it may be an effective way of proving shelter on wide open spaces. A specifically designed umbrella may also be used with improved integrated circuit. The cost analysis for such umbrella varies with components being used.

\section{Acknowledgement}

This thesis has no funding from external sources and all the research and article writing was undertaken by the authors themselves. The research undertaken was selffunded by the authors. We would like to thank the Departments of Mechanical Engineering at Dwarkadas J. Sanghvi College of Engineering and Lokmanya Tilak College of Engineering. There are no competing interests between the authors or any third-party organization.

\section{Funding Sources}

There were no external funding sources for the paper.

\section{Authors Contributions}

Meher Dev Gudela: Conceived the idea and laid the foundation for the idea. The design and analysis of the components of the umbrella was done entirely by him. Also handled the revision and editing of the final manuscript draft

Atharv Kulkarni and Abhishek Dhotre: Handled the literature review and the base draft of the manuscript

Meher Dev Gudela and Kshitiz Shrimali: Handled the design calculations of the paper and materials research for the umbrella.

\section{Ethics and Conflicts of Interests}

There is no conflict of interests between the participating authors.

\section{References}

Carlisle, R. P. (2004). Scientific American inventions and discoveriees: all the milestones in ingenuityfrom the discovery of fire to the invention of the microwave oven. said.

Day, S. T. (1985). U.S. Patent No. 4,534,374. Washington, DC: U.S. Patent and Trademark Office.

Engst, C., Chhokar, R., Miller, A., Tate, R. B., \& Yassi, A. (2005). Effectiveness of overhead lifting devices in reducing the risk of injury to care staff in extended care facilities. Ergonomics, 48(2), 187-199. 
Gingerich, B. S., \& Ondeck, D. A. (1998). Pocket guide for the home care aide. Jones \& Bartlett Learning.

Hui, L., Ng, G. Y., Yeung, S. S., \& Hui-Chan, C. W. (2001). Evaluation of physiological work demands and low back neuromuscular fatigue on nurses working in geriatric wards. Applied ergonomics, 32(5), 479-483.

Li, W. Y. (2011). U.S. Patent No. 8,061,374. Washington, DC: U.S. Patent and Trademark Office.

Martinec, A. E. C. (2011). U.S. Patent No. 7,909,048. Washington, DC: U.S. Patent and Trademark Office.

Meng, S. H., Huang, A. C., Lee, C. J., Huang, T. J., \& Dal, J. N. (2017, November). Design for intelligent control system of curtain based on Arduino. In International Conference on Smart Vehicular Technology, Transportation, Communication and Applications (pp. 178-184). Springer, Cham.

Nelson, A., Matz, M., Chen, F., Siddharthan, K., Lloyd, J., \& Fragala, G. (2006). Development and evaluation of a multifaceted ergonomics program to prevent injuries associated with patient handling tasks. International journal of nursing studies, 43(6), 717-733.
OHSAH. (2004). Memorandum of understanding with regards to manual patient handling between the association of unions and health employers association of British Columbia. Vancouver. B. Occupational Health and Safety Agency for Healthcare in British Columbia, British Colombia.

Portis Jr, M. N., \& Hampton, O. (2013). U.S. Patent No. 8,497,656. Washington, DC: U.S. Patent and Trademark Office.

Smith-Temple, J., \& Johnson, J. Y. (2005). Nurses' guide to clinical procedures.

Vaghela, M., Shah, H., Jayswal, H., \& Patel, H. (2017). Arduino based auto street light intensity controller. Invention Rapid: Embedded Systems, 2013(3), 1-4.

XRF. (2018). What is a Hydraulic Press?. XRF.

Yassi, A., Cooper, J. E., Tate, R. B., Gerlach, S., Muir, M., Trottier, J., \& Massey, K. (2001). A randomized controlled trial to prevent patient lift and transfer injuries of health care workers. Spine, 26(16), 1739-1746.

Yassi, A., Gilbert, M., \& Cvitkovich, Y. (2005). Trends in injuries, illnesses and policies in Canadian healthcare workplaces. Canadian journal of public health, 96(5), 333-339. 